\title{
RELAY, Ramucirumab Plus Erlotinib Versus Placebo Plus Erlotinib in Patients with Untreated, Epidermal Growth Factor Receptor Mutation-Positive, Metastatic Non-Small-Cell Lung Cancer: Safety Profile and Manageability
}

\author{
Ernest Nadal ${ }^{1}$ (1) - Hidehito Horinouchi ${ }^{2}$. Jin-Yuan Shih ${ }^{3} \cdot$ Kazuhiko Nakagawa $^{4}$. Martin Reck ${ }^{5}$. Edward B. Garon ${ }^{6}$. \\ Yu-Feng Wei $^{7}$. Jens Kollmeier ${ }^{8}$. Bente Frimodt-Moller ${ }^{9}$. Emily Barrett ${ }^{10} \cdot$ Olga Lipkovich $^{11}$. Carla Visseren-Grul ${ }^{12}$. \\ Silvia Novello ${ }^{13}$
}

Accepted: 17 October 2021 / Published online: 20 December 2021

(c) The Author(s) 2021

\begin{abstract}
Introduction RELAY was a global, double-blind, placebo-controlled phase III study that demonstrated superior progressionfree survival (PFS) for ramucirumab plus erlotinib (RAM + ERL) versus placebo plus erlotinib (PBO + ERL) in the first-line treatment of patients with epidermal growth factor receptor (EGFR) exon 19 deletion or exon 21 (L858R) mutation-positive, metastatic non-small-cell lung cancer (NSCLC).

Objective This article provides an in-depth analysis of the safety profile of RAM + ERL versus PBO + ERL observed in RELAY.

Methods Eligible patients met these criteria: stage IV NSCLC; EGFR exon 19 deletion or exon 21 substitution (L858R) mutation; Eastern Cooperative Oncology Group performance status 0 or 1; and no central nervous system metastases. Patients were randomized (1:1) to receive erlotinib $150 \mathrm{mg} /$ day orally plus either ramucirumab $10 \mathrm{mg} / \mathrm{kg}$ intravenously or matching placebo once every 2 weeks, until disease progression or unacceptable toxicity. The primary endpoint was PFS. Safety was evaluated based on reported treatment-emergent adverse events (AEs) and clinical laboratory assessments.

Results The safety population comprised 446 patients (221 in RAM+ERL arm; 225 in PBO + ERL arm) who received at least one dose of study drug between January 2016 and February 2018. The overall incidence of grade $\geq 3$ AEs was higher with RAM + ERL than with PBO + ERL, primarily driven by grade 3 hypertension. Grade $\geq 3$ dermatitis acneiform and diarrhea were also reported more frequently in the RAM + ERL arm. The increased incidence of AEs with RAM + ERL was easily detected through routine monitoring and managed through dose adjustments and appropriate supportive care.

Conclusion This in-depth safety analysis from RELAY supports that RAM + ERL, irrespective of the increased incidence of AEs, does not affect a patient's ability to benefit from treatment.
\end{abstract}

Clinical Trial Registration Number NCT02411448.

\section{Introduction}

Metastatic non-small-cell lung cancer (NSCLC) with activating epidermal growth factor receptor (EGFR) mutations is a serious and life-threatening disease in which all patients will eventually develop treatment resistance and disease progression on current standard-of-care therapy [1,2]. One strategy to further improve outcomes in these patients is to combine an EGFR-tyrosine kinase inhibitor (TKI) with a

Ernest Nadal

esnadal@iconcologia.net

Extended author information available on the last page of the article vascular endothelial growth factor (VEGF) signaling pathway inhibitor [3]. VEGF plays a key role in tumor angiogenesis, and dual blockade of the EGFR and VEGF receptor (VEGFR) pathways in EGFR mutation-positive NSCLC has demonstrated improved tumor control compared with $E G F R$ inhibition alone [4-7].

Ramucirumab, a human immunoglobulin G1 monoclonal antibody targeting VEGFR2 has, as a single agent or in combination with different chemotherapy regimens, been approved for second-line treatment of NSCLC, gastric or gastroesophageal junction adenocarcinoma, colorectal cancer, and hepatocellular carcinoma. More recently, ramucirumab in combination with erlotinib (RAM + ERL) has 


\section{Key Points}

This in-depth safety analysis from the RELAY trial supports that ramucirumab plus erlotinib (RAM + ERL), irrespective of an increased incidence of adverse events (AEs), did not affect the possibility of a patient benefiting from treatment.

RAM+ERL did not lead to more treatment discontinuation due to AEs, despite an overall higher incidence of grade $\geq 3 \mathrm{AEs}$, including in the subgroup of patients aged $\geq 70$ years. Overall, the AEs were manageable and the safety profile of RAM + ERL was consistent with expectations based on the established safety profile of the individual treatment components. The safety profile by race (Asian and non-Asian) was similar to that of the overall population.

RAM + ERL offers a tolerable and effective option for the first-line treatment of epidermal growth factor receptor exon 19 deletion or exon 21 (L858R) mutationpositive metastatic non-small-cell lung cancer.

been approved for first-line treatment of metastatic $E G F R$ exon 19 deletion or exon 21 (L858R) mutation-positive NSCLC based on a randomized phase III study (RELAY). In RELAY, RAM + ERL showed superior progressionfree survival (PFS) versus placebo plus erlotinib (PBO + ERL; median PFS 19.4 vs. 12.4 months; hazard ratio [HR] $0.59 ; 95 \%$ confidence interval $[\mathrm{CI}] 0.46-0.76 ; p<0.0001$ ). Safety was consistent with the established safety profiles of the individual compounds and a metastatic NSCLC population [8].

Anti-angiogenic treatment is associated with a specific adverse event profile because of the inhibition of the VEGF/ VEGFR2 signaling pathway. This article provides an indepth analysis of the safety profile of RAM + ERL versus $\mathrm{PBO}+$ ERL observed in RELAY, focusing on manageability and the resource utilization of patients. These assessments are important for informed decision making by clinicians and patients.

\section{Methods}

\subsection{RELAY Study Design}

The study design and patient eligibility have been previously published [8]. Briefly, RELAY was a global, doubleblind, placebo-controlled phase III study (clinicaltrials.gov NCT02411448). Eligible patients met the following criteria: stage IV NSCLC; eligible for first-line treatment with erlotinib on the basis of EGFR exon 19 deletion or exon 21 (L858R) mutation; Eastern Cooperative Oncology Group performance status of 0 or 1; measurable disease according to RECIST 1.1 (Response Evaluation Criteria in Solid Tumors) [20]; and adequate hematological and organ function with a urinary protein $\leq 1+$ on dipstick or routine urinalysis. Exclusion criteria included known EGFR T790M mutation, central nervous system metastases, uncontrolled hypertension, and history of significant bleeding. Further eligibility criteria are available in the electronic supplementary material (ESM) pp 1. Patients were randomized (1:1) to receive either intravenous ramucirumab $10 \mathrm{mg} / \mathrm{kg}$ or matching placebo every 2 weeks plus oral erlotinib $150 \mathrm{mg}$ daily. Premedication with a histamine $\mathrm{H}_{1}$ antagonist was required prior to infusion of ramucirumab or placebo.

Patients continued therapy until progression, unacceptable toxicity, withdrawal of consent, noncompliance, or investigator decision. All patients provided written informed consent, and the study was approved by all relevant ethical committees.

\subsection{Assessments and Procedures}

Safety was evaluated based on reported treatment-emergent adverse events (AEs) and clinical laboratory assessments. Hematology, serum chemistry, and urine analysis were performed prior to every cycle, and the coagulation profile every four cycles or more frequently, as clinically indicated.

AEs and resource utilization were monitored throughout the study treatment period and for 30 days post treatment discontinuation. Unresolved serious AEs (SAEs) related to study treatment or protocol procedures were monitored during the long-term follow-up period until resolution, loss to follow-up, or death.

AEs were coded using the Medical Dictionary for Regulatory Activities and graded using the National Cancer Institute-Common Terminology Criteria for Adverse Events, version 4.0 (NCI-CTCAE v4.0). Clinical laboratory results were graded using NCI-CTCAE v4.0 and summarized by worst grade severity.

The study protocol specified monitoring and handling of AEs, including guidelines for dose adjustments based on the observed toxicity assessment. Protocol-required dose modifications for treatment-related toxicities are shown in ESM pp. 1. According to the protocol, step-wise reduction of ramucirumab/placebo dosing to 8,6 , or $5 \mathrm{mg} / \mathrm{kg}$ and erlotinib to 100 or $50 \mathrm{mg} /$ day because of AEs was allowed. Treatment with ramucirumab/placebo could be delayed for up to 42 days, and ERL for up to 3 weeks, to enable recovery from AEs. If RAM or PBO were discontinued because of AEs, the patient could remain on ERL; similarly, patients could continue to receive RAM or PBO if ERL was discontinued. 


\subsection{Analyses}

Safety was assessed in all patients who received at least one dose of study treatment. Results were analyzed descriptively by study treatment arm (RAM + ERL or PBO + ERL) and included the following: duration of therapy and number of infusions per patient; relative dose intensities (\%), calculated as the actual amount of drug taken / amount of drug planned per protocol $\times 100$; the proportion of patients with AEs; and summaries of AEs for the prespecified patient subgroups of age ( $<70$ and $\geq 70$ years) and race (Asian and non-Asian). Exposure-adjusted incidence rates were calculated for selected AEs to adjust for the observed difference in exposure (treatment duration) between treatment arms using the following formula: incidence rate $/ 100 \mathrm{PY}=n / \mathrm{PY} \times 100$, where PY is person-year, defined as the sum of individual patient treatment durations converted to the unit of year, and $n=$ number of patients with the AE. Association analyses between selected events (e.g., proteinuria and renal failure) were evaluated [27] computing odds ratios with exact CIs using Fisher's exact test [9].

Resource utilization data included hospitalization incidence rates, the total number of days in hospital, the proportion of patients receiving at least one transfusion and the type of transfusion and the proportion of patients receiving supportive care during the study treatment period.

No formal statistical testing was conducted for these safety analyses.

\section{Results}

\subsection{Patient Population}

Data cutoff was 23 January 2019. A total of 449 patients were enrolled. The safety population comprised 446 patients (221 in the RAM + ERL arm and 225 in the PBO + ERL arm), as three patients in the RAM + ERL arm did not receive treatment. Baseline characteristics were balanced between the two treatment arms [8]. Median follow-up time was 20.7 months (range $0.1-35.4$ ).

\subsection{Exposure}

In a censored analysis (patients still on study treatment were censored at the time of data cutoff), the median duration of exposure was 12.4 months for ramucirumab, 10.1 months for placebo, and 15.1 versus 11.2 months for erlotinib in the RAM + ERL versus PBO + ERL arms, respectively (Table 1). The median relative dose intensity of each study drug was high (>90\%) and comparable between treatment arms.

\subsection{Treatment-emergent Adverse Event Profile Overview}

All patients reported at least one $\mathrm{AE}$, the majority of which were grade 1-2 in severity (Fig. 1). AEs (any grade) occurring in $\geq 20 \%$ of patients in the RAM+ERL arm and with a $\geq 10 \%$ higher incidence than in the PBO + ERL arm were hypertension, alanine aminotransferase (ALT) increased, aspartate aminotransferase (AST) increased, alopecia, proteinuria, epistaxis, and peripheral edema (Fig. 1). The overall incidence of grade $\geq 3$ AEs was higher with RAM + ERL than with PBO + ERL, primarily driven by grade 3 hypertension. The grade $\geq 3$ AEs that occurred at a $\geq$ $5 \%$ higher incidence with RAM + ERL than with PBO + ERL were hypertension, dermatitis acneiform, and diarrhea. These events were all grade 3 in severity; none were grade 4 or 5 . The incidence of grade 4 events was low and similar between treatment arms ( $5 \%$ for RAM + ERL vs. $4 \%$ for PBO + ERL). The most common grade 4 events were ALT increased and abnormal hepatic function [8]. Grade 5 events are discussed in Sect. 3.4.

\subsection{Serious adverse events (SAEs)}

A higher percentage of patients treated with RAM + ERL than with PBO + ERL experienced SAEs. Most SAEs occurred in one patient each (Fig. 2). The most common any-grade SAEs occurring in two or more patients and with $\mathrm{a} \geq 1 \%$ higher incidence in the RAM + ERL than PBO + ERL arm were pneumonia, cellulitis, decreased appetite, and diarrhea. With the exception of decreased appetite, these SAEs were also the most common grade $\geq 3$ SAEs.

Six deaths in the RAM + ERL arm and none in the PBO + ERL arm were due to adverse events during study treatment or within 30 days of treatment discontinuation (Table 2). Only one (hemothorax) was assessed as related to study treatment by the investigator. This occurred 28 days after the last dose of ramucirumab in a patient who had undergone thoracic drainage for pleural empyema 6 days previously. Three of the deaths considered not related (renal failure and two cases of pneumonia) occurred several months after discontinuation of ramucirumab and while on erlotinib. For the two remaining deaths (influenza-associated encephalitis and lymphoma), there was no biological plausibility suggesting a causal relationship with ramucirumab.

\subsection{AEs of Special Interest}

\subsubsection{Overview}

The AEs of special interest (AESI) are prespecified groups of AEs potentially associated with anti-angiogenic agents that inhibit VEGF or VEGFR2 signaling pathways or that 
Table 1 Exposure to study treatments and overall dose adjustments in RELAY

\begin{tabular}{|c|c|c|c|c|}
\hline \multirow[t]{2}{*}{ Study treatment exposure and dose adjustments } & \multicolumn{2}{|c|}{$\operatorname{RAM}+\operatorname{ERL}(n=221)$} & \multicolumn{2}{|c|}{$\mathrm{PBO}+\mathrm{ERL}(n=225)$} \\
\hline & RAM & ERL & $\mathrm{PBO}$ & ERL \\
\hline Duration of therapy (months) ${ }^{\mathrm{a}}$ & $12.4(0.5-33.8)$ & $15.1(0.0-33.8)$ & $10.1(0.5-35.4)$ & $11.2(0.4-35.5)$ \\
\hline Infusions received per patient & $21.0(1.0-69.0)$ & NA & $19.0(1.0-74.0)$ & NA \\
\hline Relative dose intensity $(\%)^{\mathrm{b}}$ & $94.5(42.9-112.1)$ & $92.3(30.2-100)$ & $97.7(54.2-106.7)$ & $96.3(27.9-100)$ \\
\hline Patients with at least one dose adjustment & $168(76.0)$ & $143(64.7)$ & $133(59.1)$ & $134(59.6)$ \\
\hline Patients with a dose reduction & $23(10.4)$ & $99(44.8)$ & $4(1.8)$ & $96(42.7)$ \\
\hline One dose reduction & $14(6.3)$ & $64(29.0)$ & $3(1.3)$ & $71(31.6)$ \\
\hline Two dose reductions & $7(3.2)$ & $31(14.0)$ & $1(0.4)$ & $22(9.8)$ \\
\hline Three or more dose reductions & $2(0.9)$ & $4(1.8)$ & 0 & $3(1.3)$ \\
\hline \multicolumn{5}{|l|}{ Reasons leading to dose reductions } \\
\hline $\mathrm{AE}$ & $23(10.4)$ & $96(43.4)$ & $4(1.8)$ & $93(41.3)$ \\
\hline Others & 0 & $10(4.5)$ & 0 & $10(4.4)$ \\
\hline Patients with a dose delay ${ }^{\mathrm{c}}$ & $147(66.5)$ & NA & $121(53.8)$ & NA \\
\hline One dose delay & $50(22.6)$ & NA & $50(22.2)$ & NA \\
\hline Two dose delays & $33(14.9)$ & NA & $31(13.8)$ & NA \\
\hline Three or more dose delays & $64(29.0)$ & NA & $40(17.8)$ & NA \\
\hline \multicolumn{5}{|l|}{ Reasons leading to dose delays } \\
\hline $\mathrm{AE}$ & $140(63.3)$ & NA & $102(45.3)$ & NA \\
\hline Scheduling conflict & $32(14.5)$ & NA & $37(16.4)$ & NA \\
\hline Patients with a dose omission & $62(28.1)$ & $119(53.8)$ & $28(12.4)$ & $118(52.4)$ \\
\hline One dose omission & $50(22.6)$ & $51(23.1)$ & $18(8.0)$ & $54(24.0)$ \\
\hline Two dose omissions & $8(3.6)$ & $24(10.9)$ & $3(1.3)$ & $29(12.9)$ \\
\hline Three or more dose omissions & $4(1.8)$ & $44(19.9)$ & $7(3.1)$ & $35(15.6)$ \\
\hline \multicolumn{5}{|l|}{ Reasons leading to dose omissions } \\
\hline $\mathrm{AE}$ & $48(21.7)$ & $116(52.5)$ & $20(8.9)$ & $113(50.2)$ \\
\hline Others & $17(7.7)$ & $34(15.4)$ & $11(4.9)$ & $30(13.3)$ \\
\hline
\end{tabular}

Data are presented as median (range) or $n(\%)$ unless otherwise indicated. The data cutoff date was 23 January 2019

$A E$ treatment-emergent adverse events, $E R L$ erlotinib, $N$ number of patients, $n$ number of patients in the specified category, $N A$ not applicable, $P B O$ placebo, $R A M$ ramucirumab

${ }^{a}$ Data are from a censored analysis in which 64 patients in the RAM +ERL arm and 43 patients in the PBO + ERL arm were censored because of continuing study treatment

${ }^{b}$ Relative dose intensity was calculated as (actual amount of drug taken / amount of drug planned per protocol) $\times 100$

${ }^{\mathrm{c}}$ Dose delays of erlotinib were not captured on the case report form

were observed in preclinical or clinical studies of ramucirumab [10-15]. These include hypertension, proteinuria, bleeding/hemorrhage, and liver failure/injury ("hepatic events").

The majority of these AESIs were low grade in severity (Fig. 3); the incidence of AESIs over time is presented in Fig. 4.

\subsubsection{Hypertension}

The incidence of hypertension was higher in the RAM + ERL arm than in the PBO + ERL arm (any grade: 45 vs. $12 \%$; grade $\geq 3: 24$ vs. $5 \%$ ). The differences between arms remained following exposure-adjusted incidence analysis. No cases of malignant hypertension or hypertensive crisis were noted. The majority of patients experiencing hypertension in both treatment arms had a single event (any grade: 87 vs. $85 \%$; grade $\geq 3: 98$ vs. $75 \%$; RAM + ERL vs. $P B O+$ ERL, respectively). Approximately one-half of the patients who experienced a grade $\geq 3$ event in both arms had a prior history of hypertension. The two SAEs of grade 3 hypertension were reported in the RAM + ERL arm only. Neither of the serious hypertension events led to secondary cardiac or cerebrovascular complications.

Hypertension was generally reversible and was managed with antihypertensive therapy and/or dose modifications as clinically indicated per protocol. Consistent with the higher incidence of hypertension, more patients in the RAM + ERL arm than in the PBO + ERL arm received supportive antihypertensive therapies (69 vs. $42 \%$, respectively) (Table 3). A 
Fig. 1 Treatment-emergent adverse events occurring in $\geq 20 \%$ of patients in the RAM + ERL arm in RELAY. ERL erlotinib, $P B O$ placebo, $R A M$ ramucirumab

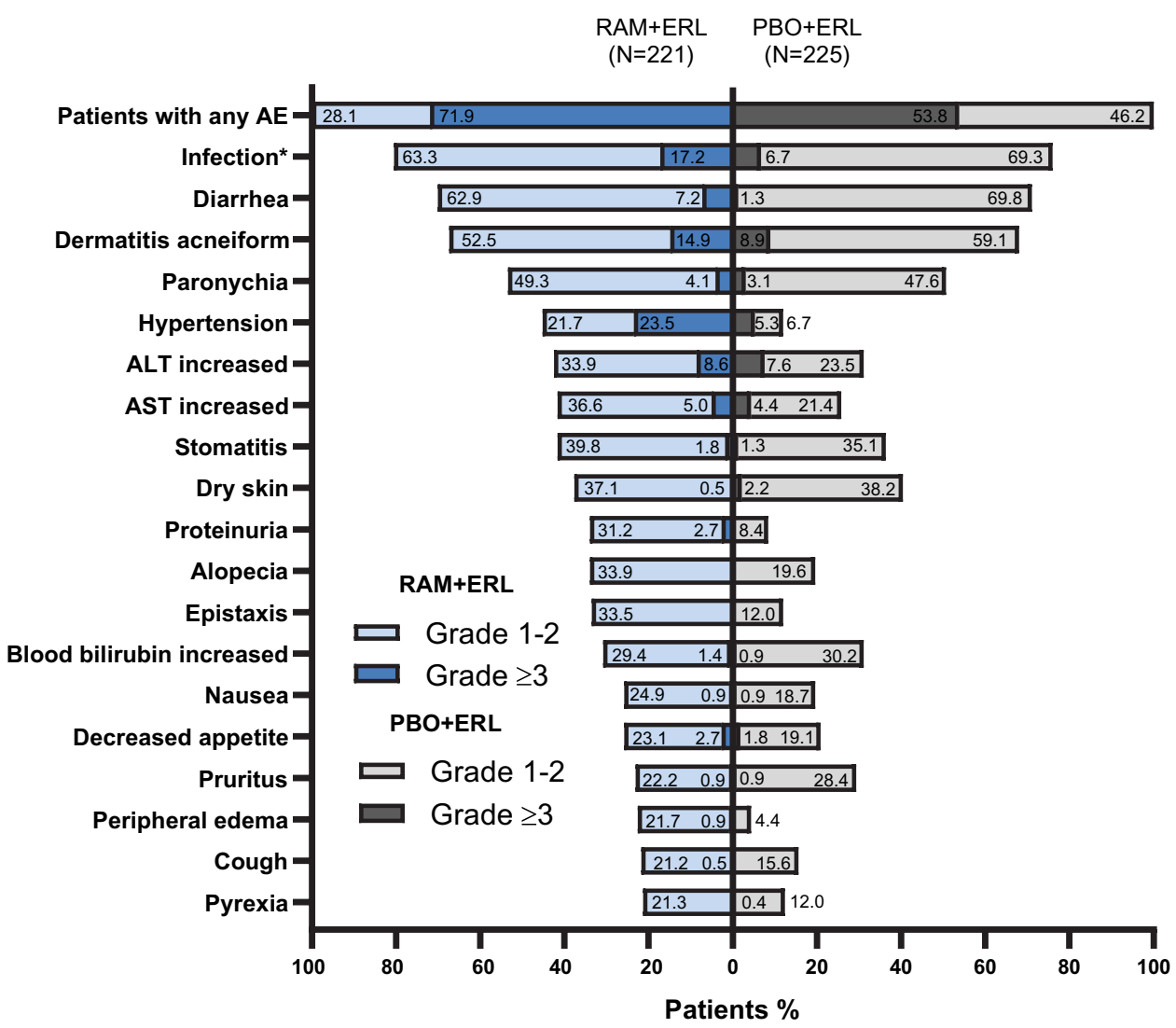

${ }^{*}$ Composite term; pneumonia was the only Grade $\geq 3$ infection $A E$ to occur at a $\geq 2 \%$ higher rate with RAM+ERL compared with PBO+ERL

$\mathrm{AE}=$ treatment-emergent adverse event; $\mathrm{ALT}=$ alanine aminotransferase; $\mathrm{AST}=$ aspartate aminotransferase

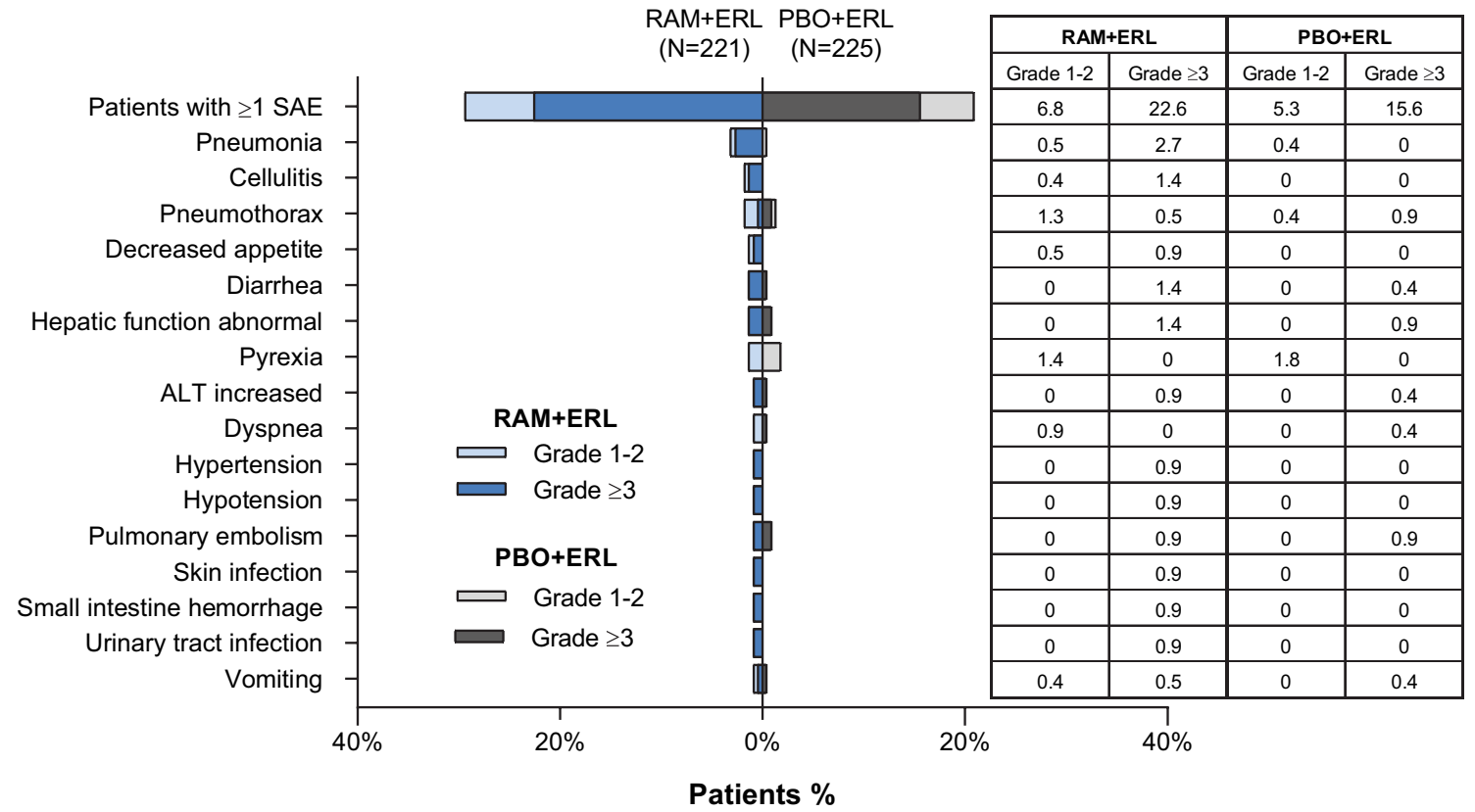

SAE = serious adverse event $; A L T=$ alanine aminotransferase.

Fig. 2 Serious adverse events reported in two or more patients in the RAM + ERL arm in RELAY. ERL erlotinib, $P B O$ placebo, $R A M$ ramucirumab 
small proportion of patients $(5 \%)$ had ramucirumab or placebo dose adjustments because of hypertension (Fig. 5). One patient in each treatment arm discontinued ramucirumab (grade 2) or placebo (grade 3) alone because of hypertension. The median number of ramucirumab or placebo infusions was similar to the median number of infusions in the overall safety population.

Additional analyses showed that the occurrence of hypertension in the RAM + ERL arm was not associated with either preexisting hypertension, headache, cardiovascular,
Fig. 4 Number of patients experiencing adverse events of special interest (all grades) over time in RELAY: a hypertension, b proteinuria, $\mathbf{c}$ bleeding/hemorrhage, $\mathbf{d}$ hepatic events, $\mathbf{e}$ dermatitis, and $\mathbf{f}$ diarrhea. The frequencies of selected adverse events across treatment cycles were plotted by treatment arm using a stacked bar chart, where each bar represents one cycle and comprises four mutually exclusive groups: patients without events and patients with events of maximum grades 1,2 , or $\geq 3$ in a given cycle. Plots are presented by treatment arm. ERL erlotinib, $P B O$ placebo, $R A M$ ramucirumab

Table 2 Deaths due to adverse events while receiving study treatment or within 30 days of all study treatment discontinuation

\begin{tabular}{|c|c|c|}
\hline Adverse event (age) & Therapy at time of AE & Event details \\
\hline $\begin{array}{l}\text { Hemothorax } \\
\text { ( } 57 \text { years) }\end{array}$ & RAM, ERL & $\begin{array}{l}\text { Event start: day } 74 \text { ( } 28 \text { days after last dose of RAM); } 5 \text { days after thoracic drainage for pleural } \\
\text { empyema }\end{array}$ \\
\hline $\begin{array}{l}\text { Renal failure } \\
\text { (66 years) }\end{array}$ & ERL & $\begin{array}{l}\text { Event start: day } 846 \text { (202 days after last dose of RAM); medical history: bilateral hydrone- } \\
\text { phrosis }\end{array}$ \\
\hline $\begin{array}{l}\text { Pneumonia } \\
\text { ( } 74 \text { years) }\end{array}$ & ERL & $\begin{array}{l}\text { Event start: day } 483 \text { ( } 454 \text { days after last dose of RAM); medical history: ex-smoker and VATS } \\
\text { partial lung resection }\end{array}$ \\
\hline $\begin{array}{l}\text { Pneumonia bacterial } \\
\text { ( } 65 \text { years) }\end{array}$ & ERL & $\begin{array}{l}\text { Event start: day } 318 \text { ( } 141 \text { days after last dose of RAM; } 5 \text { days after last dose of ERL); medical } \\
\text { history: ex-smoker, COPD, recurrent pneumothorax, bulla ligation, lung infections }\end{array}$ \\
\hline $\begin{array}{l}\text { Encephalitis influenza } \\
\text { (59 years) }\end{array}$ & RAM, ERL & Event start: day 9 ( 9 days after one dose of RAM); confirmed on microbiological testing \\
\hline $\begin{array}{l}\text { Lymphoma } \\
\text { (53 years) }\end{array}$ & RAM, ERL & $\begin{array}{l}\text { Event start: day } 80 \text { of treatment; non-biopsy proven: small intestinal lymphoma following } \\
\text { abdominal CT scan for melena; discontinued all study treatments because of progressive } \\
\text { lung cancer day } 92 \text {; died day } 97\end{array}$ \\
\hline
\end{tabular}

$C O P D$ chronic obstructive pulmonary disease, $C T$ computed tomography, ERL erlotinib, RAM ramucirumab, VATS video-assisted thorascopic surgery

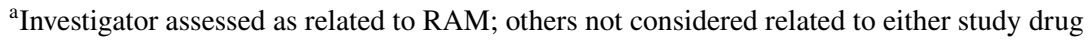

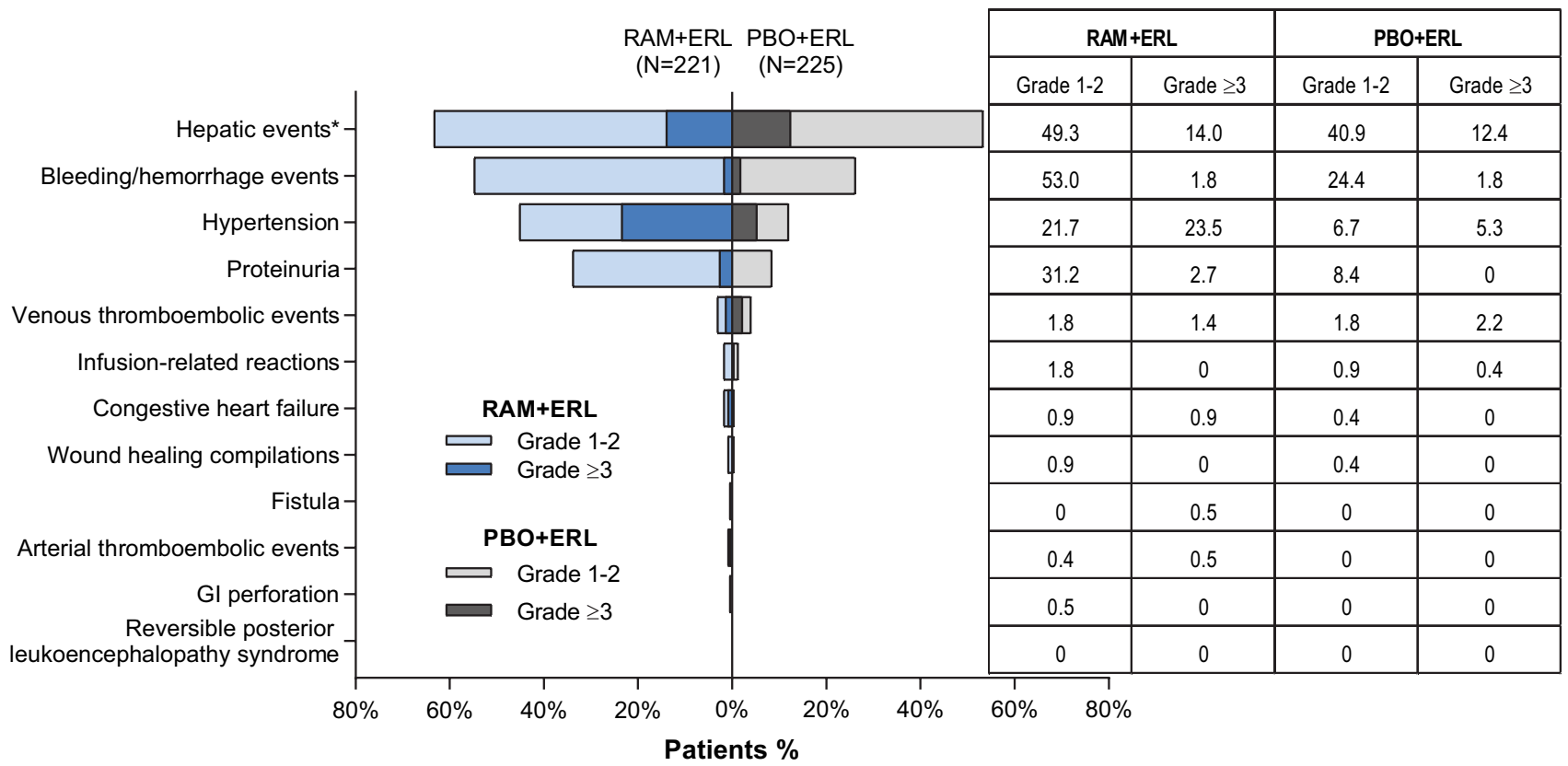

${ }^{\star} \mathrm{AE}$ of special interest term - liver failure/liver injury; $\mathrm{GI}$ = gastrointestinal

Fig. 3 Treatment-emergent adverse events of special interest in RELAY. ERL erlotinib, $P B O$ placebo, $R A M$ ramucirumab 
a
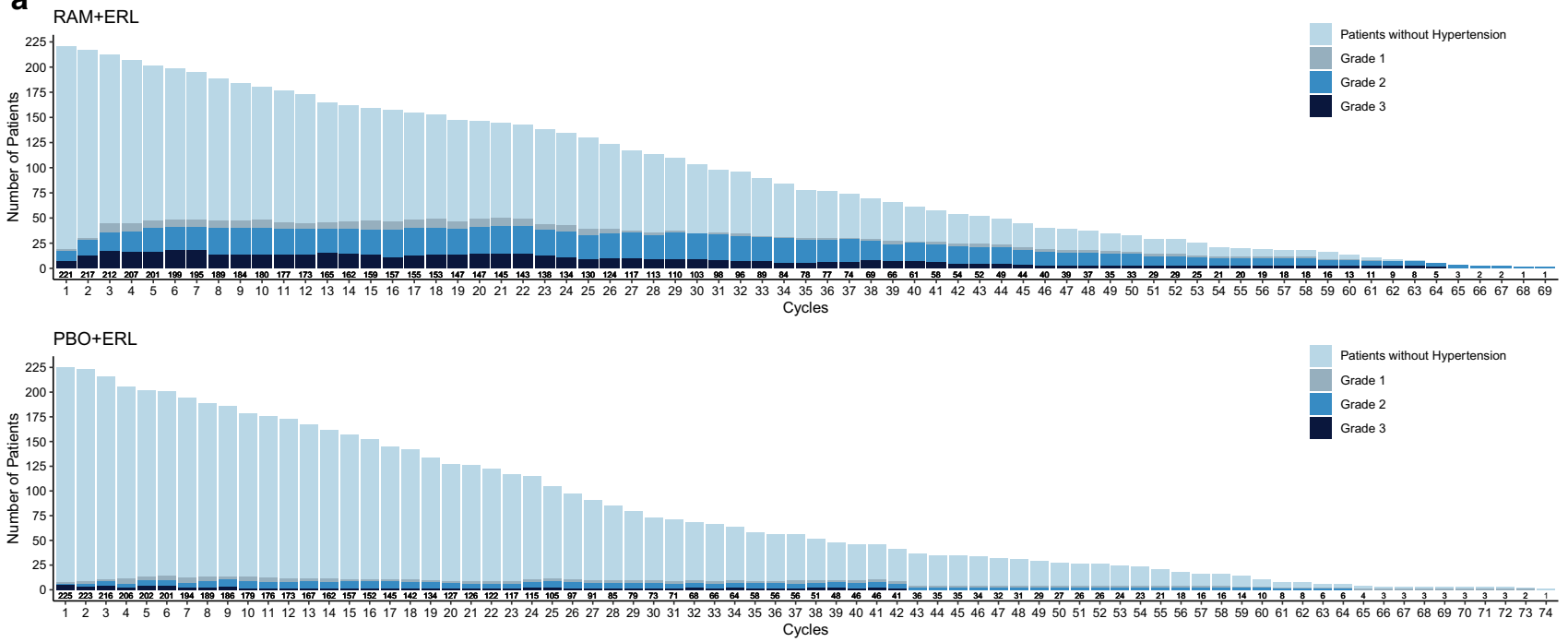

\section{b}
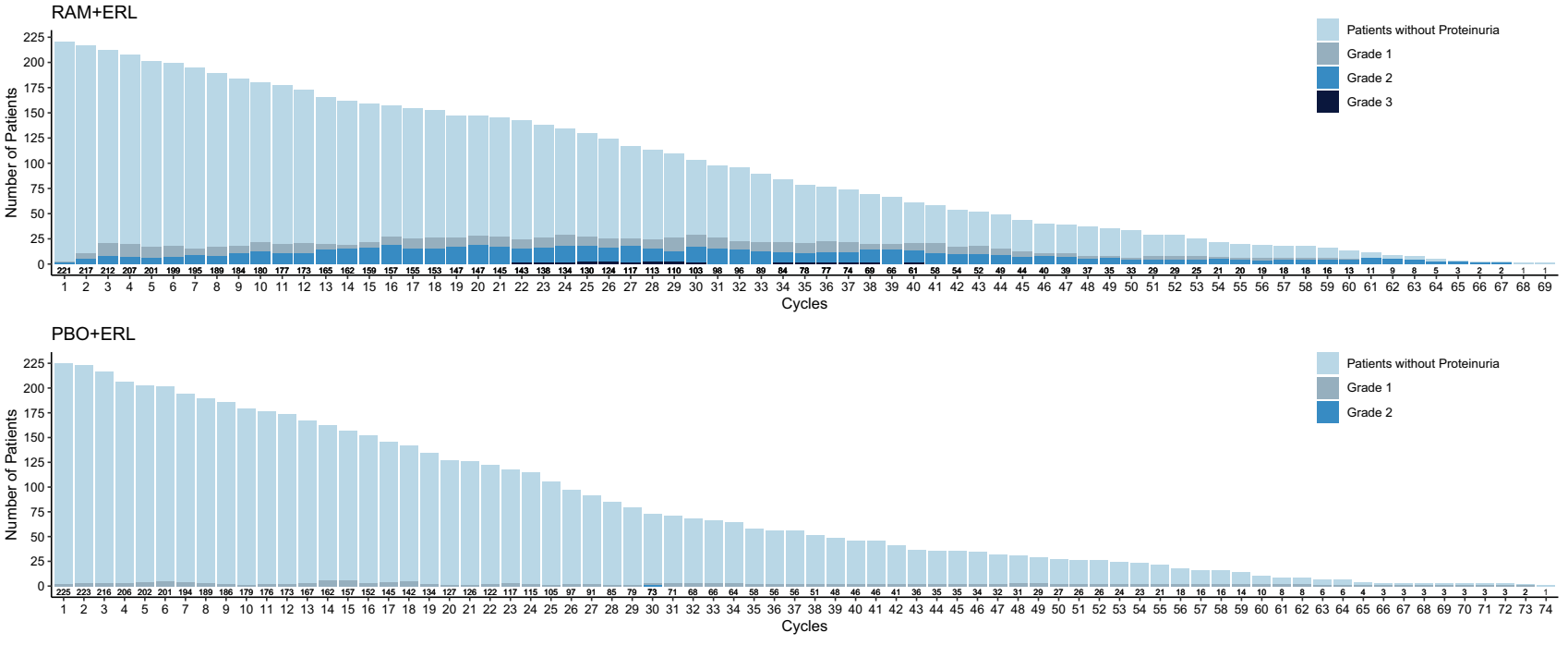

C
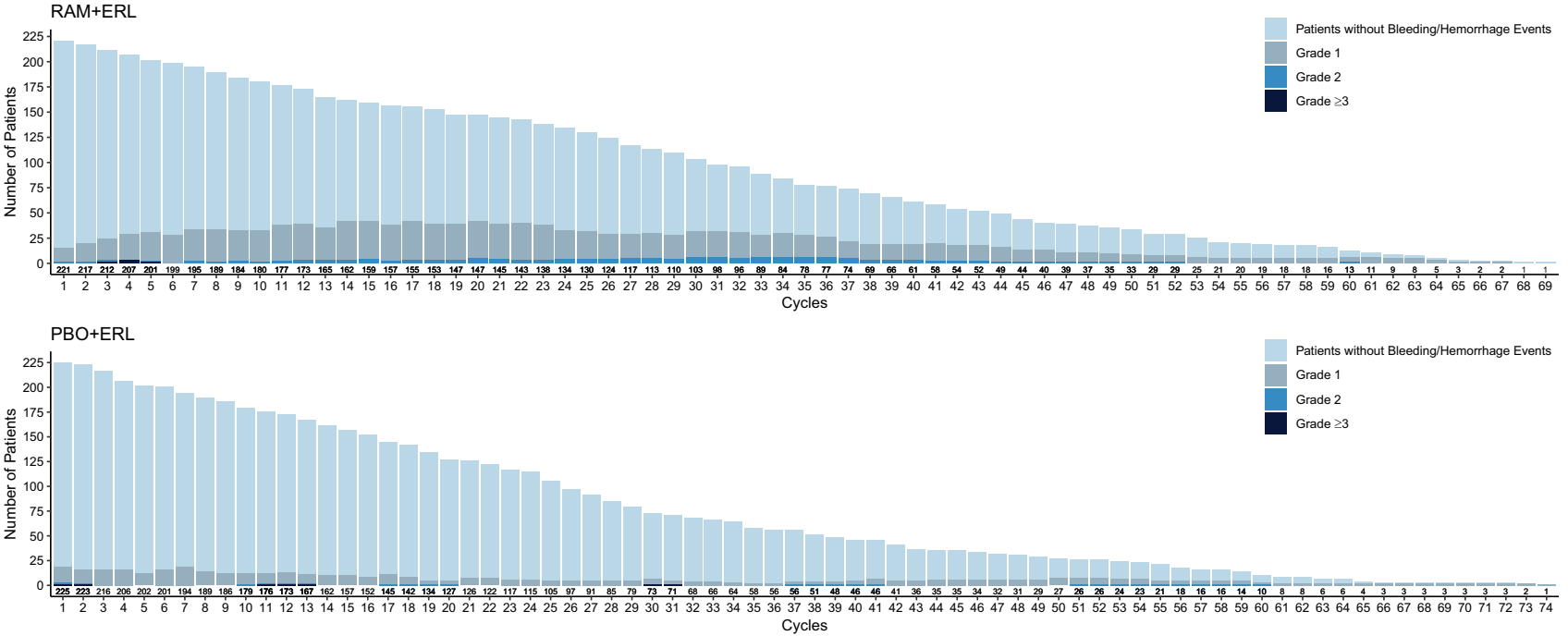

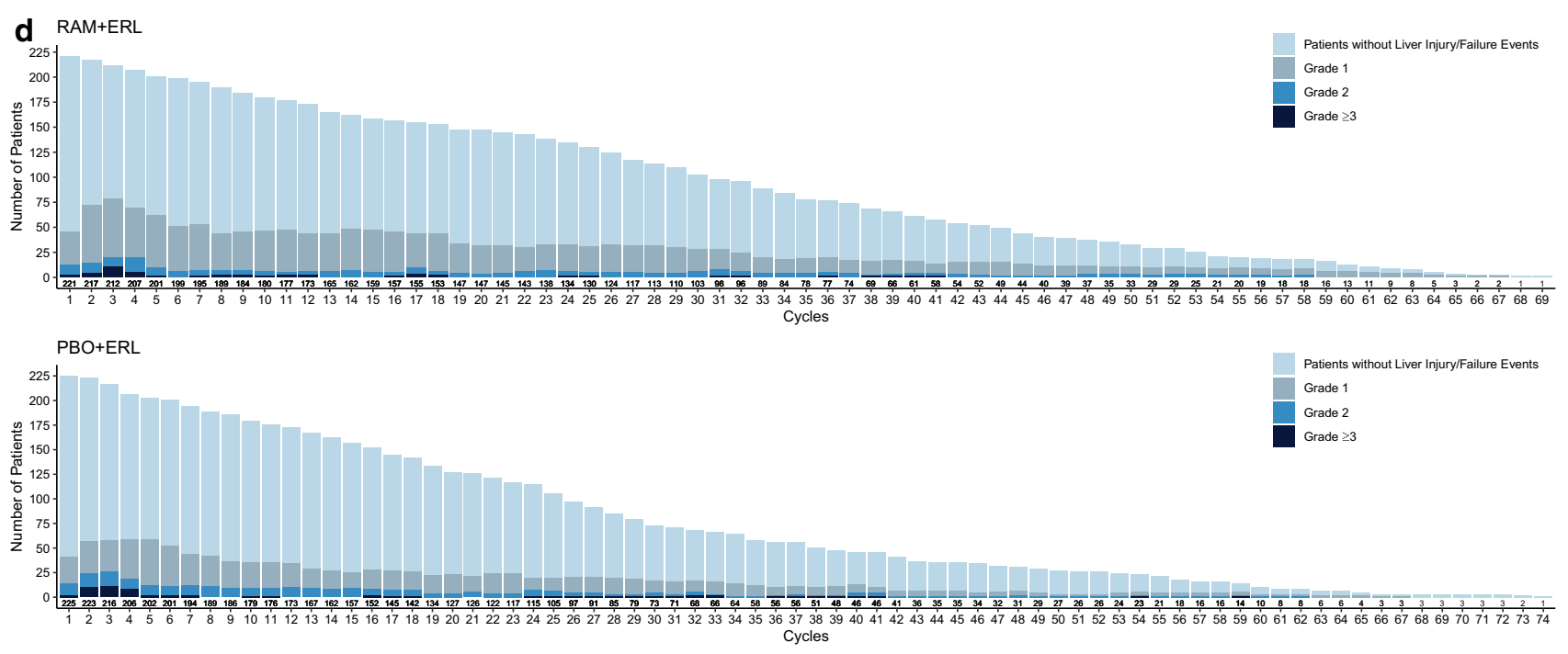

e RAM+ERL
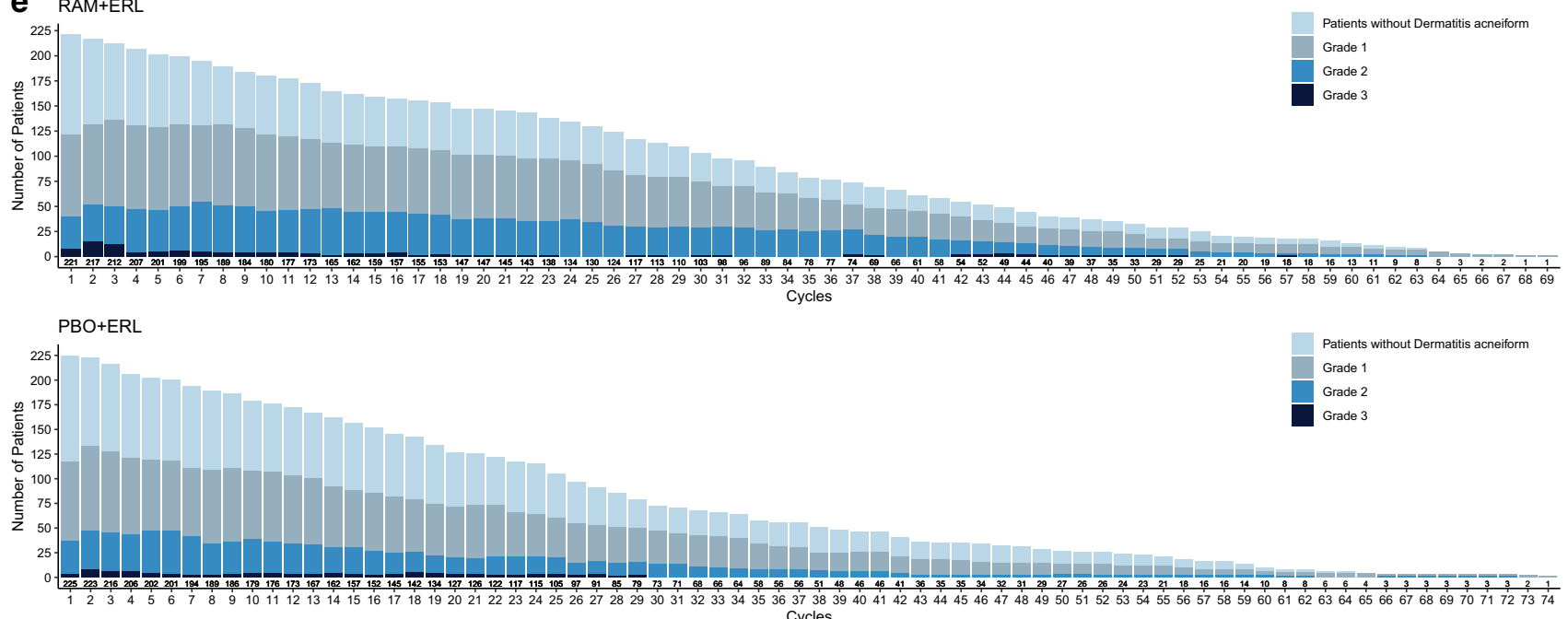

f RAM+ERL
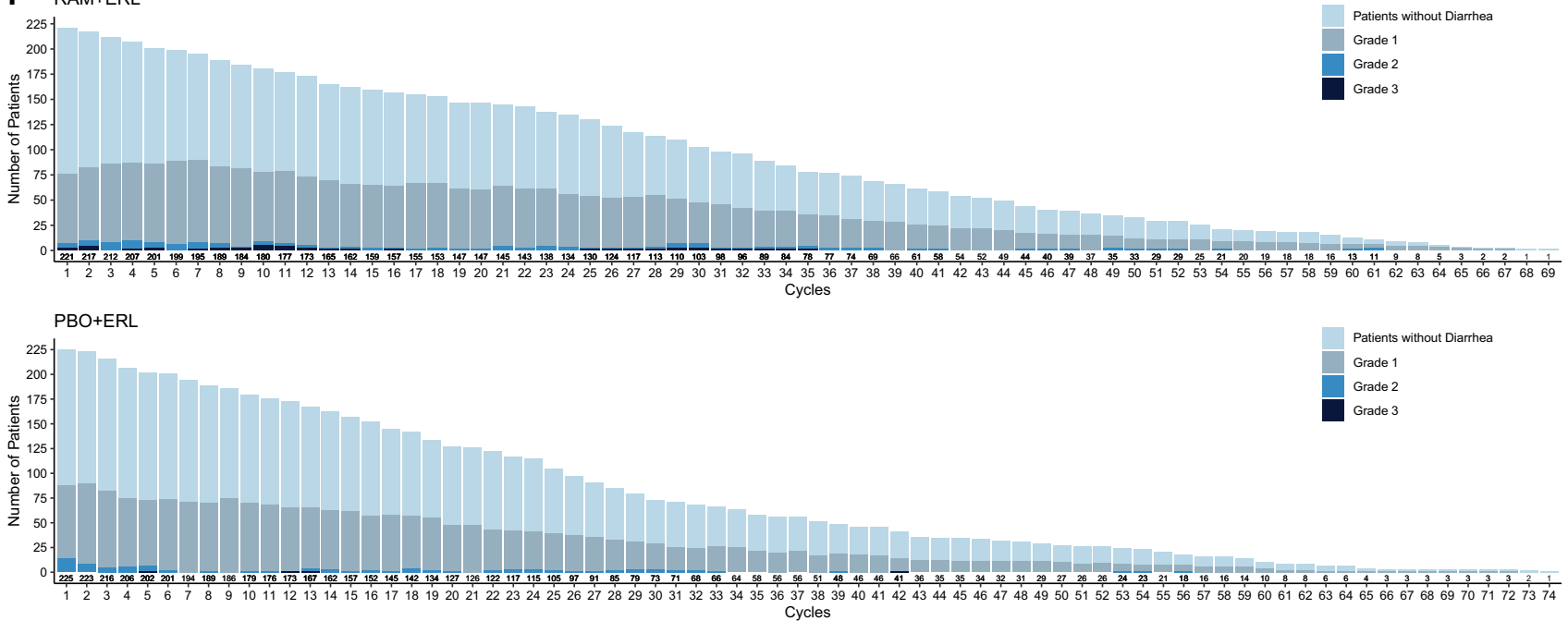

Fig. 4 (continued) 
or cerebrovascular conditions but was associated with proteinuria and epistaxis.

\subsubsection{Proteinuria}

The incidence of any-grade proteinuria was higher with RAM + ERL than with PBO + ERL (34 vs. 8\%). This difference between arms remained following adjustment of incidence for exposure. The vast majority of proteinuria events were low grade. Grade $\geq 3$ proteinuria was reported in $3 \%$ of patients, all in the RAM + ERL arm and all grade 3 in severity. Only one patient in the RAM + ERL arm experienced serious proteinuria. No patients experienced nephrotic syndrome.

Proteinuria was the most common AE leading to dose adjustments of ramucirumab (12\%), with no dose adjustments occurring in the PBO + ERL arm (Fig. 5). In total, $1 \%$ of patients discontinued all study treatment and $9 \%$ of patients discontinued RAM alone (Fig. 6). In patients who experienced any-grade proteinuria, the median number of ramucirumab or placebo infusions received was similar between treatment arms (ramucirumab 27.0 [range 2.0-67.0] vs. placebo 24.0 [range 2.0-73.0], respectively) and was similar to the median number of ramucirumab or placebo infusions in the overall safety population.

As would be expected clinically, association analyses indicated that proteinuria was associated with peripheral edema. An association was also observed between the occurrence of proteinuria and hypertension. No association was found between proteinuria and renal failure.

\subsubsection{Bleeding/Hemorrhage}

The incidence of any-grade bleeding/hemorrhage was higher with RAM + ERL than with PBO + ERL (55 vs. $26 \%$, respectively) (Fig. 7), mainly driven by low-grade epistaxis, followed by gingival bleeding. The incidence of grade $\geq 3$ bleeding events was similar between treatment arms (2\%). Following exposure-adjusted incidence analysis, similar differences of any-grade and grade $\geq 3$ bleeding events were noted between treatment arms. No grade 4 or 5 events occurred in either treatment arm.

The incidence of any-grade pulmonary hemorrhage was higher with RAM + ERL than with PBO + ERL (7 vs. 2\%) (Fig. 7), primarily driven by grade 1 hemoptysis (5 vs. $\leq$ $0.5 \%)$. Grade $\geq 3$ pulmonary bleeding was low $(\leq 0.5 \%)$, regardless of treatment arm. There was one grade 5 hemothorax in the RAM + ERL arm (Sect. 3.4). These differences between arms for pulmonary hemorrhage remained following exposure-adjusted incidence analysis.

SAEs were observed mainly as singular events in seven $(\mathrm{RAM}+\mathrm{ERL})$ and two $(\mathrm{PBO}+\mathrm{ERL})$ patients, with the
Table 3 Treatment-emergent adverse event-associated resource use in RELAY

\begin{tabular}{lcl}
\hline Resource use & $\begin{array}{c}\text { RAM + ERL } \\
(n=221)\end{array}$ & $\begin{array}{l}\text { PBO + ERL } \\
(n=225)\end{array}$ \\
\hline Hospitalizations & & \\
Patients hospitalized due to AEs & $66(29.9)$ & $44(19.6)$ \\
Duration of hospitalization, days & $12(1-67)$ & $11(2-36)$ \\
Transfusions & & \\
Any transfusion & $8(3.6)$ & 0 \\
Packed red blood cells & $7(3.2)$ & 0 \\
Platelets & $2(0.9)$ & 0 \\
Supportive care & & \\
Dermatological products & $195(88.2)$ & $202(89.8)$ \\
$\quad$ Topical steroids & $176(79.6)$ & $187(83.1)$ \\
$\quad$ Emollients and protectives & $133(60.2)$ & $128(56.9)$ \\
Antibiotics & $92(41.6)$ & $77(34.2)$ \\
Systemic antimicrobials & $194(87.8)$ & $192(85.3)$ \\
$\quad$ Antibiotics & $191(86.4)$ & $190(84.4)$ \\
Antivirals & $19(8.6)$ & $19(8.4)$ \\
$\quad$ Antifungals & $7(3.2)$ & $4(1.8)$ \\
Analgesics & $173(78.3)$ & $147(65.3)$ \\
Antihypertensives & $153(69.2)$ & $95(42.2)$ \\
Calcium channel antagonists & $110(49.8)$ & $56(24.9)$ \\
Angiotensin II inhibitors & $108(48.9)$ & $60(26.7)$ \\
$\quad$ Diuretics & $49(22.2)$ & $16(7.1)$ \\
$\mathrm{H}_{1}$ antagonists & $135(61.1)$ & $123(54.7)$ \\
Antidiarrheals & $130(58.8)$ & $126(56.0)$ \\
Acid suppressants/protectants & $116(52.5)$ & $109(48.4)$ \\
Stomatological preparations & $103(46.6)$ & $82(36.4)$ \\
Systemic corticosteroids & $77(34.8)$ & $84(37.3)$ \\
Antiemetics & $76(34.4)$ & $63(28.0)$ \\
Antihemorrhagics & $30(13.6)$ & $13(5.8)$ \\
Bone modifiers & $29(13.1)$ & $25(11.1)$ \\
Anticoagulants & $19(8.6)$ & $12(5.3)$ \\
Antiplatelets & $17(7.7)$ & $16(7.1)$ \\
Appetite stimulants & $12(5.3)$ \\
Granulocyte colony-stimulating & $10.4)$ \\
\hline
\end{tabular}

Data are presented as $n(\%)$ or median (range)

$A E$ treatment-emergent adverse event, $E R L$ erlotinib, $H_{l}$ histamine receptor $1, P B O$ placebo, $R A M$ ramucirumab

exception of small intestinal hemorrhage reported in two patients in the RAM + ERL arm (Fig. 2).

Dose adjustments of ramucirumab or placebo for bleeding or hemorrhage were reported in 5 versus $2 \%$ of patients, respectively, with a similar percentage of dose adjustments due to grade $\geq 3$ events, regardless of treatment arm. The rate of discontinuation of all study treatment due to bleeding/hemorrhage events was low and similar between treatment arms. Four patients discontinued ramucirumab alone (grade 1 hemoptysis, grade 2 epistaxis, grade 2 melena, and 


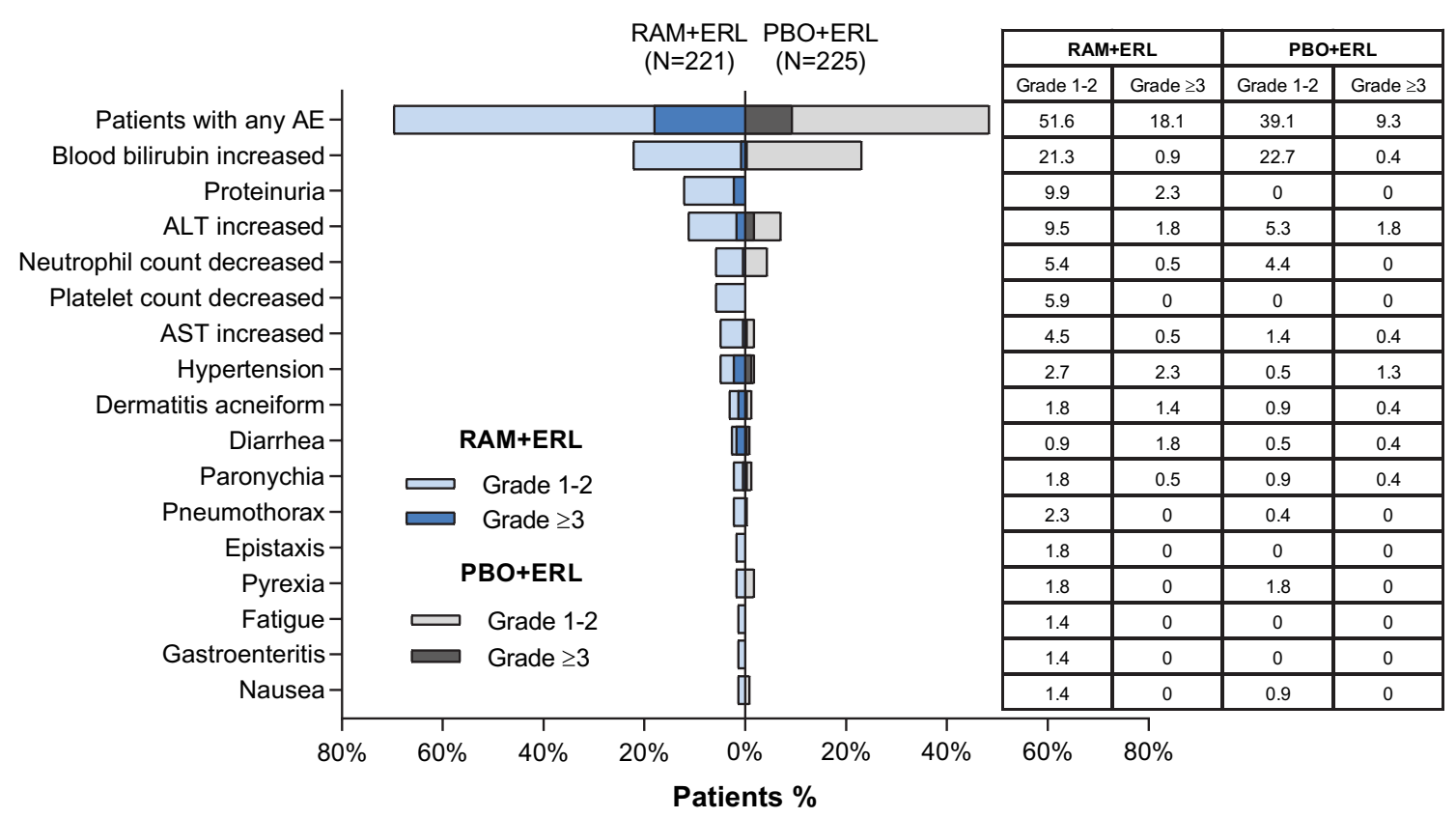

$\mathrm{AE}=$ treatment-emergent adverse event; $\mathrm{ALT}=$ alanine aminotransferase $; \mathrm{AST}=$ aspartate aminotransferase

Fig. 5 Any-grade treatment-emergent adverse events leading to ramucirumab or placebo dose adjustment in three or more patients in the RAM + ERL arm in RELAY. ERL erlotinib, $P B O$ placebo, $R A M$ ramucirumab

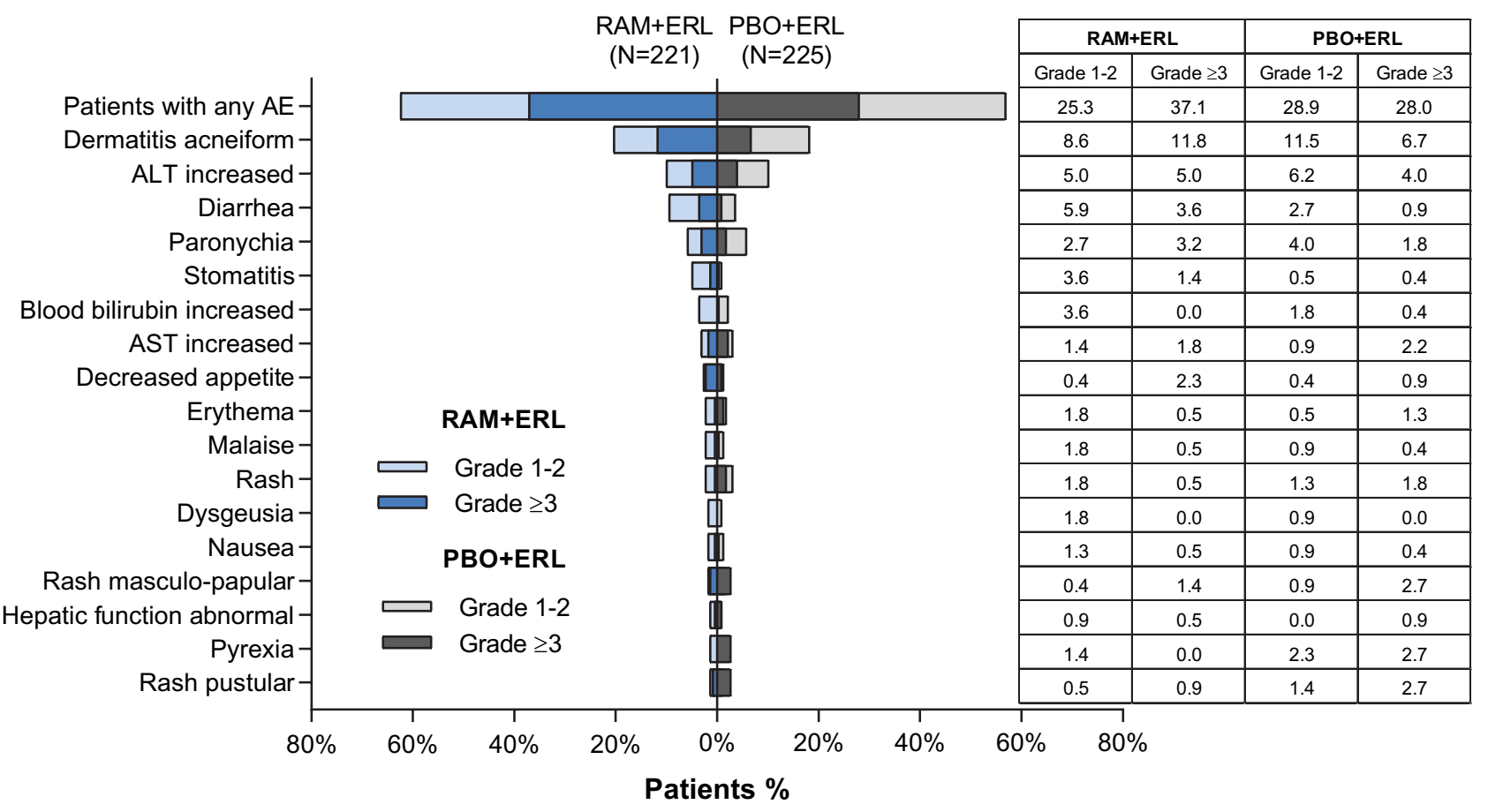

$\mathrm{AE}=$ treatment-emergent adverse event $; \mathrm{ALT}=$ alanine aminotransferase $; \mathrm{AST}=$ aspartate aminotransferase

Fig. 6 Any-grade treatment-emergent adverse events leading to erlotinib dose adjustment in three or more patients in the RAM + ERL arm in RELAY. ERL erlotinib, $P B O$ placebo, $R A M$ ramucirumab 


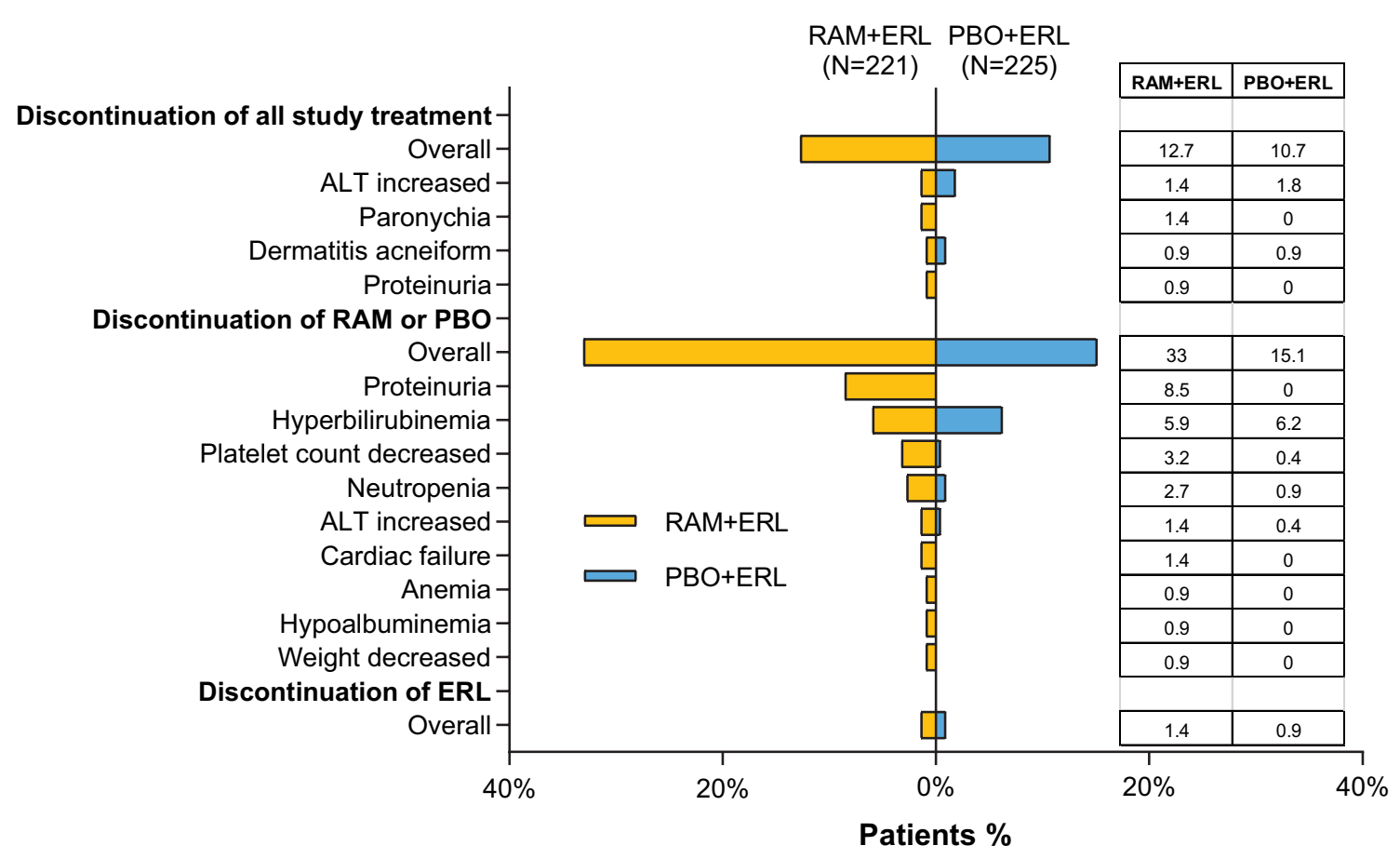

$\mathrm{ALT}=$ alanine aminotransferase

Fig. 7 Any-grade treatment-emergent adverse events leading to treatment discontinuation in two or more patients in the RAM + ERL arm in RELAY. ERL erlotinib, $P B O$ placebo, RAM ramucirumab

grade 3 small intestine hemorrhage), and one patient discontinued placebo alone (grade 3 hematuria).

Use of antihemorrhagic medications was greater in the RAM + ERL arm than in the PBO + ERL arm (14 vs. 6\%). Additionally, $3 \%$ patients in the RAM + ERL arm only required a blood transfusion (packed red blood cells).

An association analysis showed no correlation between concomitant or recent (within previous 2 weeks) use of anticoagulant therapy and bleeding/hemorrhagic events. No association was observed between thrombocytopenia and bleeding in the RAM + ERL arm. Furthermore, the use of nonsteroidal anti-inflammatory drugs was not related with a higher bleeding risk in the RAM + ERL arm. Bleeding/ hemorrhage was associated with anemia.

\subsubsection{Hepatic Events}

AEs of liver failure/liver injury ("hepatic events") were the most frequently reported AESIs, regardless of treatment arm. The majority were laboratory events, primarily driven by low-grade increase in ALT, AST, and serum bilirubin (Fig. 7). The incidence of any-grade hepatic events was higher in the RAM + ERL arm, whereas the rate of grade $\geq 3$ hepatic events was similar in the two treatment arms (Fig. 7). The differences between arms in hepatic events were maintained following exposure-adjusted incidence rate analysis.

Dose adjustments for ramucirumab alone due to hepatic events were higher than for placebo alone adjustments (Fig. 5). There was a similar rate of dose adjustments for erlotinib in the RAM + ERL and PBO + ERL arms (19 vs. $17 \%$, respectively). Discontinuation from all study treatment because of a hepatic event occurred infrequently in the RAM + ERL (2\%) and PBO + ERL (4\%) arms. A similar proportion of patients discontinued ramucirumab/ placebo alone because of hepatic events. One patient in the RAM + ERL arm discontinued erlotinib because of grade 2 ALT increased.

\subsubsection{Other AEs of Special Interest}

No meaningful difference in incidence between treatment arms was observed for the other AESIs (Fig. 3). Arterial and venous thromboembolic events, infusion-related reactions, congestive heart failure, wound healing complications, gastrointestinal perforation, fistula, and reversible posterior leukoencephalopathy syndrome were all reported in $<1 \%$ of patients. 


\subsection{Other AEs of Interest}

Infections are commonly recognized adverse drug reactions for erlotinib. In RELAY, the incidence of any-grade infections (composite term) was similar between treatment arms, whereas a higher rate of grade $\geq 3$ infections was observed with RAM + ERL than with PBO + ERL (17 vs. $7 \%$, respectively). The only grade $\geq 3$ infection occurring with a higher incidence with RAM+ERL than with $\mathrm{PBO}+$ ERL was pneumonia (3 vs. 0\%, respectively). Two grade 4 $(1 \%)$ events (septic shock and sepsis) and three (2\%) grade 5 events (pneumonia, bacterial pneumonia, and influenzaassociated encephalitis) were reported; none were assessed as related to study drugs by the investigator (see Sect. 3.4). Nine SAEs $(4 \%)$ of lower respiratory tract infections occurred in the RAM + ERL arm compared with two (1\%) in the PBO + ERL arm. Predisposing factors for pulmonary infection were identified in the majority of cases.

Systemic antimicrobial use was high and similar between treatment arms ( 88 vs. $85 \%$ ), whereas the use of granulocyte colony-stimulating factor was low and comparable between treatment arms $(<1 \%$ in both arms).

The majority of infection events occurred in one or two patients each, and no specific pattern was observed. No association between concurrent neutropenia and infection events, including severe infections and lung infections, was observed.

\subsection{Erlotinib AEs of Interest}

Infections, skin reactions of rash and dermatitis acneiform, diarrhea, interstitial lung disease (ILD), and paronychia are clinically relevant events associated with erlotinib that occur commonly and/or are potentially overlapping toxicities between erlotinib and ramucirumab. These events were assessed for any potential additional toxicity when erlotinib and ramucirumab were used in combination.

For all erlotinib AEs of interest, the incidence of anygrade events was similar between treatment arms. The incidence of grade $\geq 3$ events of dermatitis acneiform ( $15 \mathrm{vs}$. $9 \%$ ) and diarrhea (7 vs. $1 \%$ ) was higher in the RAM + ERL arm (Fig. 1). The grade $\geq 3$ events were all grade 3 , and the incidence of erlotinib-related AESIs is presented in Fig. 7.

The most common AEs (observed in $\geq 10 \%$ of patients) and leading to erlotinib dose reductions and omissions were dermatitis acneiform and ALT increased, with similar percentages of patients reporting dose reductions or omissions between arms. Grade $\geq 3$ AEs leading to erlotinib dose adjustments occurring at a higher incidence in the RAM+ERL arm than in the PBO + ERL arm were dermatitis acneiform (12 vs. $7 \%$ ) and diarrhea (4 vs. $1 \%)$, respectively (Fig. 8).
Dermatitis acneiform did not lead to any study drug discontinuation in either treatment arm, and the vast majority of skin events were managed by topical applications (Table 3 ). Two patients in the RAM + ERL arm discontinued erlotinib because of grade 2 ALT increased and grade 3 diarrhea, respectively. One patient in the PBO + ERL arm discontinued erlotinib because of grade 2 rash pustular.

Any-grade and grade $\geq 3$ ILD were reported in four (1.8\%) patients and one $(0.5 \%)$ patient in the RAM + ERL arm and seven $(3.1 \%)$ and three $(1.3 \%)$ patients in the PBO + ERL arm, respectively. There were no grade 4 events in either treatment arm. One patient in the PBO + ERL arm experienced a grade 5 ILD event that occurred 30 days after discontinuation of study treatment and was assessed by the investigator as related to study treatment. Two patients $(0.9 \%)$ discontinued all study treatment because of ILD in the PBO + ERL arm. Two patients in the PBO + ERL arm and one patient in the RAM + ERL arm discontinued ERL alone because of ILD. No patients discontinued ramucirumab or placebo alone because of ILD while continuing erlotinib.

\subsection{Dose Adjustments}

Overall, dose adjustments occurred more frequently with ramucirumab than with placebo, whereas erlotinib dose adjustments were comparable between treatment arms. Ramucirumab or placebo dose adjustments were mainly delays, whereas erlotinib dose adjustments were all omissions and/or reductions. In both treatment arms, the most common reason for dose adjustments were AEs (Table 1). The incidence of any-grade and grade $\geq 3$ AEs leading to dose adjustments of any study drug was higher in the RAM+ERL arm than in the PBO + ERL arm (any grade: 85 vs. $71 \%$; grade $\geq 3: 43$ vs. $31 \%$ ). For ramucirumab or placebo alone, the most common AEs leading to dose adjustments were bilirubin increased, ALT increased, and proteinuria for ramucirumab and bilirubin increased, ALT increased, and neutrophil count decreased for placebo (Fig. 5). The most common AEs leading to erlotinib dose adjustments were dermatitis acneiform, ALT increased, and diarrhea in the RAM + ERL arm and dermatitis acneiform, ALT increased, and paronychia in the PBO + ERL arm (Fig. 8).

The median PFS of patients who had a ramucirumab or placebo dose adjustment was 20.8 months (95\% CI 17.8-22.2) for ramucirumab and 13.9 months (95\% CI 12.4-19.3) for placebo.

\subsection{Discontinuations}

Overall, a similar number of patients discontinued all study treatment because of an $\mathrm{AE}$ in both arms (13 vs. 11\% for 


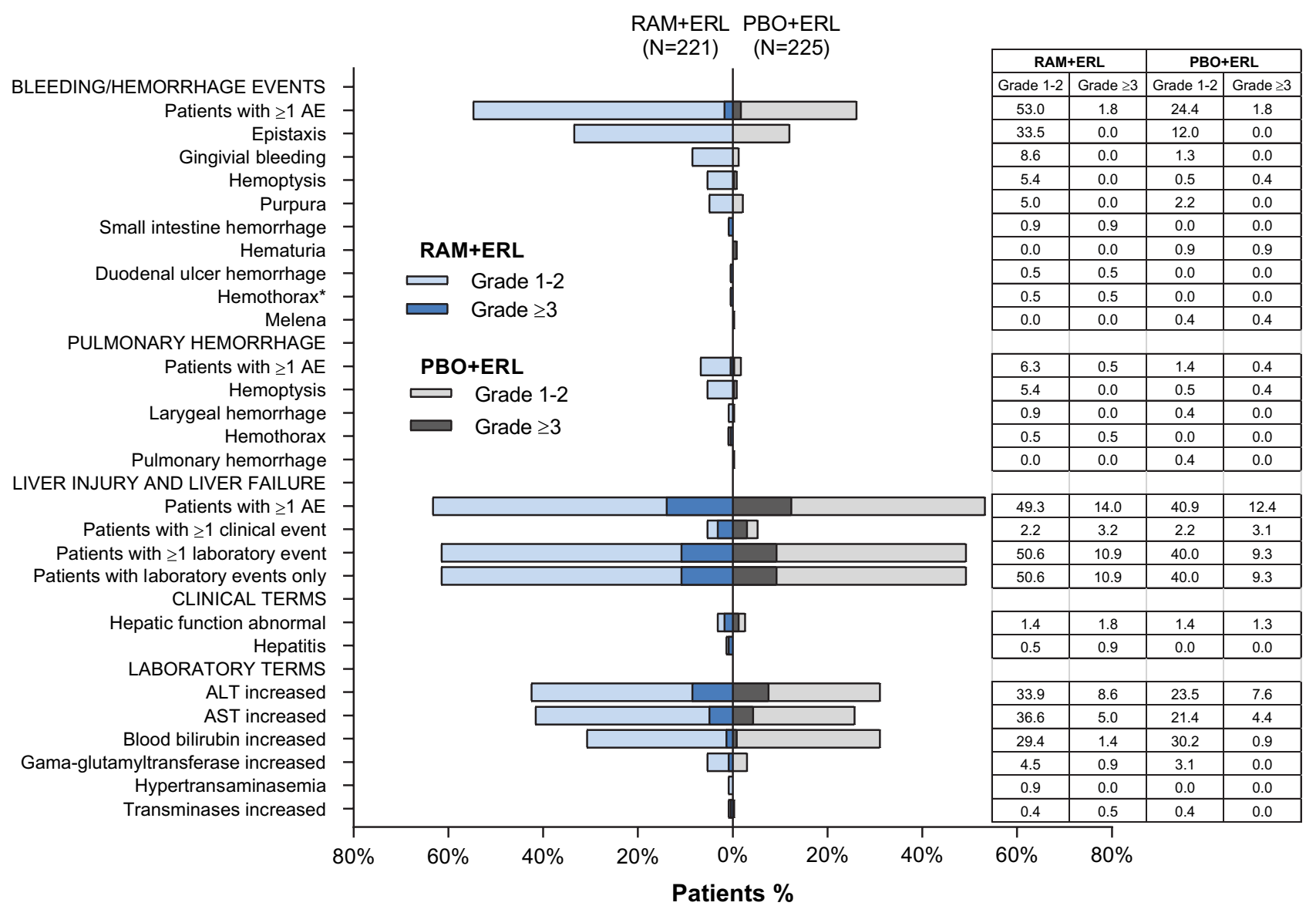

$\mathrm{AE}=$ treatment-emergent adverse event; $\mathrm{ALT}=$ alanine aminotransferase $; \mathrm{AST}=$ aspartate aminotransferase

*Grade 5 event investigator-assessed as related to RAM

Fig. 8 Bleeding/hemorrhage, pulmonary hemorrhage, and hepatic events reported in RELAY. ERL erlotinib, $P B O$ placebo, $R A M$ ramucirumab

RAM + ERL vs. PBO + ERL, respectively) (Fig. 6). Anygrade AEs leading to all study treatment discontinuation in two or more patients in the RAM + ERL arm included ALT increased, paronychia, dermatitis acneiform, and proteinuria. A higher percentage of patients discontinued ramucirumab alone (33\%) because of AEs than did so for placebo alone $(15 \%)$. The most common AEs leading to ramucirumab discontinuation observed with $\mathrm{a} \geq 2 \%$ higher incidence than for placebo discontinuation were proteinuria, decreased platelet count, and neutropenia. The incidence of AEs leading to discontinuation of erlotinib alone was low and similar between treatment arms (three vs. two patients for RAM + ERL vs. PBO + ERL, respectively) (Fig. 6). The AEs increased ALT, diarrhea, and ILD led to discontinuation of erlotinib in the RAM + ERL arm, and ILD and rash pustular led to discontinuation of erlotinib in the PBO + ERL arm. The median PFS for patients who discontinued ramucirumab or placebo early, defined as discontinuation of ramucirumab or placebo alone prior to discontinuation of all study drugs $(n=79)$, was 22.1 months (95\% CI 19.4-28.1) for the RAM + ERL arm and 12.6 months (95\% CI 9.6-19.2) for the PBO + ERL $\operatorname{arm}(n=39)$.

\subsubsection{AE Profile According to Age Group}

In RELAY, age was balanced between treatment arms, with more patients aged $<70$ years (323 patients [72\%]) than aged $\geq 70$ years (123 patients [28\%]). Independent of treatment arm, the incidence of grade $\geq 3$ AEs and SAEs was higher in patients aged $\geq 70$ than $<70$ years (Table 4 ). In the RAM+ERL arm, grade $\geq 3$ hypertension, diarrhea, and ALT increased occurred with $\mathrm{a} \geq 5 \%$ higher incidence in patients aged $\geq 70$ than in those aged $<70$ years. In patients aged $\geq 70$ years, grade $\geq 3$ hypertension and diarrhea occurred at a higher incidence in the RAM + ERL arm than in the $\mathrm{PBO}+\mathrm{ERL}$ arm, whereas in patients aged $<70$ years, only hypertension occurred at a higher incidence in the RAM + ERL versus $\mathrm{PBO}+\mathrm{ERL}$ arm.

No specific pattern of SAEs was identified between age groups. While a higher percentage of patients aged $\geq 70$ 
years experienced grade 4 AEs (8\%) compared with those aged $<70$ years $(3 \%)$, five of the six patients who had a grade $5 \mathrm{AE}$ were aged $<70$ years, and all were in the RAM + ERL arm.

Discontinuation of all study treatment was similar across age groups in both treatment arms (Table 4). More patients discontinued placebo alone in the group aged $\geq 70$ years than in the group aged $<70$ years, with a similar incidence of ramucirumab discontinuation in both age groups. Proteinuria was the most frequently reported $\mathrm{AE}$ leading to discontinuation of ramucirumab alone in both age groups.

No other differences of note were identified in terms of AE profile between treatment arms between patients aged $<$ 70 and patients aged $\geq 70$ years.

Treatment benefit was observed across all subgroups except for the smaller subset of patients (27\%) aged $\geq 70$ years, where the PFS HR was above 1 (1.042). The PFS HRs for all other age subgroups $(<65, \geq 65,<70,<75$, and $\geq$ 75 years; Fig. 1 in the ESM) were consistent with the PFS HR for the intention-to-treat group and favored the RAM + ERL treatment arm over PBO + ERL, supporting a positive risk-benefit profile for RAM + ERL, irrespective of age.

In a censored analysis of exposure, excluding patients still on treatment, patients aged $<70$ years had a higher exposure to ramucirumab or placebo in the RAM + ERL arm than in the PBO + ERL arm (13 vs. 10 months, respectively), and patients aged $<70$ years had a higher exposure to erlotinib in the RAM + ERL arm than in the PBO + ERL arm (15 vs. 11 months, respectively).

\subsubsection{AE Profile According to Race}

In RELAY, race was balanced between treatment arms, with more Asian patients enrolled overall $(n=344$ [77\%]) than non-Asian patients $(n=102$ [23\%]). The incidence of grade $\geq 3$ AEs was similar among the Asian and non-Asian groups in the RAM + ERL arm and in the non-Asian group in the PBO + ERL arm, whereas the incidence was lower in the Asian group in the PBO + ERL arm (Table 5).

The most commonly reported grade $\geq 3$ events with a higher incidence in non-Asian than in Asian patients in the RAM + ERL arm were diarrhea and hypertension. Regardless of race, a higher incidence of grade $\geq 3$ hypertension and diarrhea was seen in the RAM + ERL arm than in the $\mathrm{PBO}+\mathrm{ERL}$ arm. For dermatitis acneiform only, the Asian group in the RAM + ERL arm reported $\mathrm{a} \geq 5 \%$ higher incidence than any other group, regardless of race and treatment arm (Table 5).

Grade $\geq 3$ ALT increased was reported more frequently in the Asian group treated with PBO + ERL than in the nonAsian group (9 vs. 2\%).

ILD was reported with a similar incidence across race and treatment arm. Grade $\geq 3$ ILD events were reported only in
Asian patients regardless of treatment arm. There were no grade 4 events (Table 5).

The incidence of SAEs was higher in Asian patients in the RAM + ERL arm than in non-Asian patients within the same treatment arm and than in the PBO + ERL arm, regardless of treatment group, mostly driven by infections. Incidence of grade 5 AEs was similar between Asian and non-Asian race groups (3 vs. $2 \%$ ) in the RAM + ERL arm, with none in the PBO + ERL arm.

A similar percentage of Asian and non-Asian patients in the RAM + ERL arm and Asian patients in the PBO + ERL arm had AEs leading to discontinuation of all study treatment (Table 5). A higher percentage of Asian patients discontinued ramucirumab and placebo alone compared with non-Asian patients. Proteinuria was the most common AE leading to discontinuation of ramucirumab in both Asian and non-Asian patients.

No other differences of note were identified in terms of AE profile between treatment arms between Asian and nonAsian patients.

In a censored analysis, excluding patients still on treatment and regardless of race group, the median duration of both ramucirumab and erlotinib exposure was longer in the $\mathrm{RAM}+\mathrm{ERL}$ arm than in the PBO + ERL arm (Table 5).

\subsection{Resource Utilization}

The percentage of patients hospitalized because of AEs was higher in the RAM + ERL arm (30\%) than in the PBO + ERL arm (20\%) (Table 3). The median duration of hospitalizations because of AEs was similar for the two treatment arms (11-12 days). The most common AEs leading to hospitalization were pneumonia and pneumothorax (four cases each) in the RAM + ERL arm and pyrexia (four cases) in the PBO + ERL arm, events that are expected to occur in patients with NSCLC. No other pattern in AEs leading to hospitalization was observed. Transfusions were only reported in the RAM + ERL arm, in eight patients. Of these, seven required a packed red blood cell transfusion and two required a platelet transfusion (one patient received both). Transfusions were most frequently caused by anemia and, in one case, hemorrhage.

Overall, supportive care use was similar between arms ( 88 vs. $90 \%$ RAM + ERL vs. PBO + ERL, respectively) (Table 3). The most frequently used supportive care agents in both treatment arms were dermatological products, systemic antimicrobials, and analgesics. More antihypertensive agents were administered in the RAM + ERL arm than in the PBO + ERL arm (69 vs. 42\%), which is expected given that hypertension is a recognized $\mathrm{AE}$ for ramucirumab. Preparations for the treatment of stomatitis were administered more frequently in the RAM + ERL arm (47 vs. $36 \%$ ). This correlates with the AE-associated reporting of 
Table 4 Incidence of treatment-emergent adverse events and duration of exposure by age group

\begin{tabular}{|c|c|c|c|c|}
\hline \multirow[t]{2}{*}{ Adverse event } & \multicolumn{2}{|l|}{ RAM + ERL } & \multicolumn{2}{|l|}{$\mathrm{PBO}+\mathrm{ERL}$} \\
\hline & $\begin{array}{l}\text { Age }<70 \text { years } \\
(n=157)\end{array}$ & $\begin{array}{l}\text { Age } \geq 70 \text { years } \\
(n=64)\end{array}$ & $\begin{array}{l}\text { Age }<70 \text { years } \\
(n=166)\end{array}$ & $\begin{array}{l}\text { Age } \geq 70 \text { years } \\
(n=59)\end{array}$ \\
\hline $\mathrm{AE}$ & $157(100)$ & $64(100)$ & $166(100)$ & $59(100)$ \\
\hline Proteinuria $^{\mathrm{a}}$ & $48(30.6)$ & $27(42.2)$ & $12(7.2)$ & 7 (11.9) \\
\hline Edema peripheral $^{\mathrm{a}}$ & $30(19.1)$ & $20(31.3)$ & $4(2.4)$ & $6(10.2)$ \\
\hline Grade $\geq 3 \mathrm{AE}$ & $107(68.2)$ & $52(81.3)$ & $88(53.0)$ & $33(55.9)$ \\
\hline Hypertension $^{\mathrm{b}}$ & $33(21.0)$ & $19(29.7)$ & $6(3.6)$ & $6(10.2)$ \\
\hline Diarrhea $^{\mathrm{b}}$ & $7(4.5)$ & $9(14.1)$ & $2(1.2)$ & $1(1.7)$ \\
\hline ALT increased ${ }^{\mathrm{b}}$ & $11(7.0)$ & $8(12.5)$ & $12(7.2)$ & $5(8.5)$ \\
\hline SAE & $39(24.8)$ & $26(40.6)$ & $31(18.7)$ & $16(27.1)$ \\
\hline Diarrhea $^{\mathrm{c}}$ & 0 & $3(4.7)$ & 0 & $1(1.7)$ \\
\hline Pneumothorax $^{c}$ & $1(0.6)$ & $3(4.7)$ & $3(1.8)$ & 0 \\
\hline ALT increased ${ }^{c}$ & 0 & $2(3.1)$ & $1(0.6)$ & 0 \\
\hline Cellulitis $^{c}$ & $2(1.3)$ & $2(3.1)$ & 0 & 0 \\
\hline Decreased appetite $^{c}$ & $1(0.6)$ & $2(3.1)$ & 0 & 0 \\
\hline Pneumonia $^{c}$ & $5(3.2)$ & $2(3.1)$ & $1(0.6)$ & 0 \\
\hline Pulmonary embolism ${ }^{c}$ & 0 & $2(3.1)$ & $1(0.6)$ & $1(1.7)$ \\
\hline Discontinued all study treatment due to $\mathrm{AE}$ & $18(11.5)$ & $10(15.6)$ & $17(10.2)$ & $7(11.9)$ \\
\hline ALT increased $^{\mathrm{d}}$ & $1(0.6)$ & $2(3.1)$ & $4(2.4)$ & 0 \\
\hline Discontinued RAM/PBO alone due to $\mathrm{AE}$ & $102(65.0)$ & $44(68.8)$ & $46(27.7)$ & $22(37.3)$ \\
\hline Proteinuria $^{\mathrm{d}}$ & $30(19.1)$ & $8(12.5)$ & 0 & 0 \\
\hline Platelet count decreased ${ }^{\mathrm{d}}$ & $8(5.1)$ & $6(9.4)$ & $2(1.2)$ & 0 \\
\hline Neutropenia ${ }^{\mathrm{d}, \mathrm{e}}$ & $6(3.8)$ & $6(9.4)$ & $2(1.2)$ & $2(3.4)$ \\
\hline ALT increased ${ }^{\mathrm{d}}$ & $2(1.3)$ & $4(6.3)$ & $2(1.2)$ & 0 \\
\hline Cardiac failure $^{\mathrm{d}}$ & $2(1.3)$ & $3(4.7)$ & 0 & 0 \\
\hline Blood bilirubin increased $\mathrm{d}^{\mathrm{d}, \mathrm{f}}$ & $24(15.3)$ & $2(3.1)$ & $24(14.5)$ & $3(5.1)$ \\
\hline Weight decreased ${ }^{\mathrm{d}}$ & $2(1.3)$ & $2(3.1)$ & 0 & 0 \\
\hline Hemoptysis $^{\mathrm{d}}$ & 0 & $2(3.1)$ & 0 & 0 \\
\hline Abdominal pain upper ${ }^{\mathrm{d}}$ & 0 & $2(3.1)$ & 0 & 0 \\
\hline Epistaxis $^{\mathrm{d}}$ & 0 & $2(3.1)$ & 0 & 0 \\
\hline General physical health deterioration $^{\mathrm{d}}$ & 0 & $2(3.1)$ & 0 & 0 \\
\hline Lymphoedema $^{\mathrm{d}}$ & 0 & $2(3.1)$ & 0 & 0 \\
\hline Melena $^{\mathrm{d}}$ & 0 & $2(3.1)$ & 0 & 0 \\
\hline Discontinued ERL alone due to $\mathrm{AE}^{\mathrm{g}}$ & $1(0.6)$ & $2(3.1)$ & $2(1.2)$ & 0 \\
\hline Death due to AEs on study treatment ${ }^{\mathrm{h}}$ & $5(3.2)$ & $1(1.6)$ & 0 & 0 \\
\hline \multicolumn{5}{|l|}{ Duration of exposure, months } \\
\hline RAM/PBO & $12.7(11.0-14.1)$ & $7.8(5.6-15.1)$ & $10.1(7.4-11.1)$ & $10.8(8.3-15.4)$ \\
\hline Erlotinib & $15.1(13.8-19.3)$ & $14.3(7.3-19.5)$ & $11.1(9.7-12.2)$ & $12.4(8.9-19.3)$ \\
\hline
\end{tabular}

Data are presented as $n(\%)$ or median (95\% confidence interval). Censored analysis excluding patients still on treatment. Data cutoff date was 23 January 2019

$A E$ treatment-emergent adverse event, $A L T$ alanine aminotransferase, $E R L$ erlotinib, $P B O$ placebo, $R A M$ ramucirumab, $S A E$ serious adverse event

${ }^{a}$ Any-grade AEs occurring with a $\geq 10 \%$ higher incidence in the RAM+ERL arm in patients aged $\geq 70$ vs. $<70$ years

${ }^{\mathrm{b}}$ Grade $\geq 3$ AEs occurring with a $\geq 5 \%$ higher incidence in the RAM + ERL arm in patients aged $\geq 70$ vs. $<70$ years

${ }^{c}$ SAEs occurring in $\geq 2 \%$ patients aged $\geq 70$ years in the RAM + ERL arm

${ }^{\mathrm{d}}$ AEs occurring in $\geq 2 \%$ patients aged $\geq 70$ years in the RAM + ERL arm

${ }^{\mathrm{e}}$ Neutropenia includes neutrophil count decreased and neutropenia

${ }^{\mathrm{f}}$ Blood bilirubin increased includes hyperbilirubinemia and blood bilirubin increased

${ }^{\mathrm{g}} \mathrm{No}$ AEs occurred in $\geq 2 \%$ patients aged $\geq 70$ years in the RAM + ERL arm

${ }^{\mathrm{h}}$ Deaths during treatment and within 30 days of discontinuation 
Table 5 Incidence of treatment-emergent adverse events and duration of exposure by race group

\begin{tabular}{|c|c|c|c|c|}
\hline \multirow[t]{2}{*}{$\mathrm{AE}$} & \multicolumn{2}{|l|}{ RAM + ERL } & \multicolumn{2}{|l|}{$\mathrm{PBO}+\mathrm{ERL}$} \\
\hline & $\begin{array}{l}\text { Asian } \\
(n=170)\end{array}$ & $\begin{array}{l}\text { Non-Asian } \\
(n=51)\end{array}$ & $\begin{array}{l}\text { Asian } \\
(n=174)\end{array}$ & $\begin{array}{l}\text { Non-Asian } \\
(n=51)\end{array}$ \\
\hline $\mathrm{AE}$ & $170(100)$ & $51(100)$ & $174(100)$ & $51(100)$ \\
\hline Paronychia $^{\mathrm{a}}$ & $100(58.8)$ & $18(35.2)$ & $100(57.5)$ & $14(27.5)$ \\
\hline Proteinuria $^{\mathrm{a}}$ & $63(37.1)$ & $12(23.5)$ & $13(7.5)$ & $6(11.8)$ \\
\hline Epistaxis $^{\mathrm{a}}$ & $61(35.9)$ & $13(25.5)$ & $23(13.2)$ & $4(7.8)$ \\
\hline Platelet count decreased ${ }^{\mathrm{a}}$ & $28(16.5)$ & $3(5.9)$ & $6(3.4)$ & 0 \\
\hline Gastritis $^{\mathrm{a}}$ & $19(11.2)$ & 0 & $8(4.6)$ & $1(2.0)$ \\
\hline Grade $\geq 3 \mathrm{AE}$ & $121(71.2)$ & $38(74.5)$ & $87(50.0)$ & $34(66.7)$ \\
\hline Hypertension $^{\mathrm{b}}$ & $38(22.4)$ & $14(27.5)$ & $8(4.6)$ & $4(7.8)$ \\
\hline Diarrhea $^{\mathrm{b}}$ & $10(5.9)$ & $6(11.8)$ & $2(1.1)$ & $1(2.0)$ \\
\hline Dermatitis acneiform $^{c}$ & $31(18.2)$ & $2(3.9)$ & $15(8.6)$ & $5(9.8)$ \\
\hline \multicolumn{5}{|l|}{ Event of interest } \\
\hline ILD any grade ${ }^{\mathrm{d}}$ & $3(1.8)$ & $1(2.0)$ & $6(3.4)$ & $1(2.0)$ \\
\hline ILD grade $\geq 3^{\mathrm{d}}$ & $1(0.6)$ & 0 & $3(1.7)$ & 0 \\
\hline SAE & $54(31.8)$ & $11(21.6)$ & $40(23.0)$ & 7 (13.7) \\
\hline Infection any grade & $19(11.2)$ & $3(5.9)$ & $5(2.9)$ & $1(2.0)$ \\
\hline Infection grade $\geq 3$ & $16(9.4)$ & $3(5.9)$ & $3(1.7)$ & 0 \\
\hline Pneumonia ${ }^{\mathrm{e}}$ & $7(4.1)$ & 0 & $1(0.6)$ & 0 \\
\hline Cellulitis ${ }^{\mathrm{e}}$ & $4(2.4)$ & 0 & 0 & 0 \\
\hline Pneumothorax ${ }^{\mathrm{e}}$ & $4(2.4)$ & 0 & $3(1.7)$ & 0 \\
\hline Discontinued all study treatment because of $\mathrm{AE}^{\mathrm{f}}$ & $23(13.5)$ & $6(11.8)$ & $23(13.2)$ & $1(2.0)$ \\
\hline Discontinued RAM/PBO alone because of AE & $63(37.1)$ & $3(5.9)$ & $29(16.7)$ & $2(3.9)$ \\
\hline Proteinuria $^{\mathrm{g}}$ & $16(9.4)$ & $3(5.9)$ & 0 & 0 \\
\hline Blood bilirubin increased ${ }^{\text {gh }}$ & $12(7.1)$ & $1(2.0)$ & $12(6.9)$ & $3(5.9)$ \\
\hline Platelet count decreased ${ }^{g}$ & $6(3.5)$ & $1(2.0)$ & $1(0.6)$ & 0 \\
\hline Neutropenia ${ }^{\mathrm{gi}}$ & $5(3.0)$ & $1(2.0)$ & $2(1.1)$ & 0 \\
\hline Discontinued ERL alone because of $\mathrm{AE}^{\mathrm{f}}$ & $3(1.8)$ & 0 & $2(1.1)$ & 0 \\
\hline Death due to TEAEs on study treatment $\mathrm{t}^{\mathrm{j}}$ & $5(3.0)$ & $1(2.0)$ & $0(0)$ & $0(0)$ \\
\hline \multicolumn{5}{|l|}{ Duration of exposure, months } \\
\hline RAM/PBO & $11.3(7.8-13.8)$ & $13.8(10.1-20.7)$ & $10.4(8.2-11.4)$ & $9.8(7.4-13.5)$ \\
\hline Erlotinib & $15.1(13.1-17.9)$ & $14.8(11.1-22.9)$ & $11.3(10.4-12.4)$ & $9.8(7.8-13.8)$ \\
\hline
\end{tabular}

Data are presented as $n(\%)$ or median (95\% confidence interval). Censored analysis excluding patients still on treatment. Data cutoff date was 23 January 2019

$A E$ treatment-emergent adverse event, $E R L$ erlotinib, $I L D$ interstitial lung disease, $P B O$ placebo, $R A M$ ramucirumab, $S A E$ serious adverse event

${ }^{a}$ Any-grade AEs occurring with a $\geq 10 \%$ higher incidence in the RAM + ERL arm in Asian vs. non-Asian patients

${ }^{\mathrm{b}}$ Grade $\geq 3$ AEs occurring with $\mathrm{a} \geq 5 \%$ higher incidence in the RAM + ERL arm in Asian vs. non-Asian patients

${ }^{\mathrm{c}}$ Grade $\geq 3$ AEs occurring with $\mathrm{a} \geq 5 \%$ higher incidence in the RAM + ERL arm in non-Asian vs. Asian patients

${ }^{\mathrm{d}}$ ILD includes pneumonitis

${ }^{\mathrm{e}}$ SAEs occurring in $\geq 2 \%$ Asian patients in the RAM + ERL arm

${ }^{\mathrm{f}} \mathrm{No}$ AEs occurred in $\geq 2 \%$ Asian patients in the RAM + ERL arm

${ }^{g}$ AEs occurring in $\geq 2 \%$ Asian patients in the RAM + ERL arm

${ }^{\mathrm{h}}$ Blood bilirubin increased includes hyperbilirubinemia

${ }^{i}$ Neutropenia includes neutrophil count decreased

${ }^{\mathrm{j}}$ Deaths during treatment and within 30 days of discontinuation 
stomatitis (42 vs. $36 \%)$ and mucosal inflammation (6 vs. $3 \%$ ), both more frequent in the RAM + ERL arm. Increased use of analgesics (78 vs. $65 \%$ ) was reported in the RAM + ERL versus PBO + ERL arms, respectively. No single cause explains this difference when reviewing all indications for use, including "pain"; however, pyrexia was reported in 21 versus $12 \%$ patients, respectively, which may have contributed to this difference.

\section{Discussion}

The overall safety data for RELAY, previously reported by Nakagawa et al. [16], showed the safety profile to be consistent with the safety of the individual compounds in the advanced lung cancer setting. This report provides additional in-depth analyses of the safety data from the RELAY trial, including analyses of patients aged $<70$ years compared with those aged $\geq 70$ years and Asian patients compared with non-Asian patients.

The majority of the AESIs in RELAY were grade 1 or 2 in severity and were manageable with dose adjustments, standard pharmacological treatments, and other supportive care without impacting on the clinical benefit or the patient's ability to continue RAM + ERL treatment.

The AESIs with higher incidences in the RAM + ERL than in the PBO + ERL arm were hypertension, proteinuria, bleeding/hemorrhage, and liver failure/liver injury events. These events were observed at a higher incidence in the RAM + ERL arm than in previous ramucirumab phase III studies in different indications [10-15]. However, the event rates across indications were similar when adjusted for duration of exposure, as the median duration of ramucirumab exposure was longer in RELAY (11.0 months) than in other phase III studies (range 1.8-4.4 months) [10-15].

With the exception of liver failure/liver injury events, these AESIs are known pharmacological class-related effects commonly associated with anti-angiogenic agents and also reported in randomized phase II or III clinical trials combining the VEGF inhibitor bevacizumab with erlotinib (BEV + ERL) [4-6, 17].

The association between VEGF pathway inhibition and hypertension, proteinuria, and bleeding/hemorrhage are well described in the literature and relate to direct inhibition of nitric oxide production resulting in vasoconstriction and sodium retention for hypertension, glomerular damage for proteinuria, and reduced regenerative capacity and increased apoptosis of endothelial cells leading to endothelial dysfunction for bleeding/hemorrhage [18-20]. Hypertension is a known risk associated with anti-angiogenic treatment, although it is manageable with blood pressure monitoring and titration of antihypertensive medication. Monitoring for the development or worsening of proteinuria during ramucirumab therapy is advised. Proteinuria is reversible and manageable with dose omissions or dose reductions. The incidence of hypertension, proteinuria, or bleeding/hemorrhage varies among studies combining an anti-angiogenic with an EGFR-TKI agent. However, caution must be used when comparing studies because study designs and patient populations differ. In RELAY, the incidence of hypertension was at the lower end, and proteinuria was below the range, of that reported in the BEV + ERL arm of previous studies $[4-6,17]$. In the RAM + ERL arm of RELAY, grade $\geq 3$ hypertension was reported in $24 \%$ of the patients, whereas the range of incidences reported in patients treated in the BEV + ERL arm of studies was 23-61\% [4-6, 17]. The grade $\geq 3$ incidence of proteinuria was $3 \%$ in the RAM + ERL arm and 7-12\% in the BEV + ERL arm of studies [4-6, 17], and the incidence of grade $\geq 3$ bleeding/hemorrhage events was $2 \%$ in the RAM + ERL arm and $1-3 \%$ in the BEV + ERL arm of studies [4-6].

Presentation of safety data varies across studies. For example, in RELAY, consolidated terms were used that combined different preferred terms that report the same event, enabling more meaningful interpretation of the adverse event data. To put this into perspective, the incidence of hypertension in RELAY included the preferred term increased blood pressure and others, whereas hypertension and increased blood pressure were reported as individual terms in other studies [6]. As a result, specific event terms may appear artificially low if the reader does not identify these nuances in reporting terms. Another issue with not consolidating adverse events is that less frequent events may not be presented if the reporting threshold is too high. It is also worthwhile to note whether adverse events are reported as treatment related, particularly if the study is open label, or regardless of causality, as in the RELAY trial.

In the RAM + ERL arm, transaminase elevations had a higher incidence than observed in previous clinical trials of ramucirumab in adult patients with cancer [10-15]. This is not unexpected, as transaminase elevation is a well-recognized AE associated with EGFR-TKIs.

The incidence of other erlotinib-associated toxicities, such as skin reactions including paronychia, diarrhea, and ILD, was not higher when erlotinib was combined with ramucirumab, suggesting no additional toxicity.

The incidence of AEs leading to the discontinuation of all study treatment was similar between treatment arms (12.7 vs. $10.7 \%$, respectively), which can be viewed as a measure of how treatment is tolerated. Although $33 \%$ of the patients discontinued ramucirumab because of an $\mathrm{AE}$, this did not negatively affect outcomes, as the PFS in patients discontinuing ramucirumab early was consistent with that observed in the overall population. Similarly, dose adjustments did not affect efficacy, as the PFS outcomes for patients with dose adjustments were similar to those observed in the overall 
population. The discontinuation of erlotinib alone was negligible in both treatment arms. Other studies combining an VEGF and an EGFR-TKI reported a similar percentage of patients (approximately 30-40\%) discontinuing the VEGF component early because of AEs [4-6, 17]. The need for dose adjustments did not affect a patient's ability to benefit from treatment, as the median PFS of patients who had a ramucirumab or placebo dose adjustment (ramucirumab 20.8 months [95\% CI 17.8-22.2], placebo 13.9 months [95\% CI 12.4-19.3]) was similar to that in the overall population.

Subgroup analysis by race showed no clinically meaningful differences in the adverse event profile between treatment arms. The lack of meaningful differences in the safety profile reported between race was also documented in relation to the East-Asian and the EU/US population versus the overall RELAY population $[21,22]$. This is particularly relevant as the majority of studies investigating EGFR-TKIs and anti-angiogenics were conducted in East-Asian populations [4-6].

A higher incidence of grade $\geq 3$ AEs was observed in patients aged $\geq 70$ years in the RAM + ERL arm. The specific subset of patients aged $\geq 70$ years did not demonstrate the same magnitude of PFS treatment effect as observed in the other age subgroups $(<65, \geq 65,<70,<75$, and $\geq 75$ years). This is possibly due to chance because of the small sample size of the subgroup aged $\geq 70$ years, which might increase the magnitude of variability in incidence rates in this group. Similarly, a higher incidence of grade $\geq 3$ AEs was reported in elderly ( $\geq 75$ years) patients with advanced NSCLC who received other antiangiogenic agents such as bevacizumab plus chemotherapy [23, 24].

More patients were hospitalized in the RAM + ERL arm (30\%) than in the PBO + ERL (20\%) arm. Average days of admission were the same regardless of treatment arm. Only eight patients in the RAM + ERL arm received blood transfusion, mainly because of anemia. It is currently unclear whether this varies for other VEGF/EGFR-TKI studies as resource utilization has not been reported.

While some increased toxicity was reported with the addition of ramucirumab to erlotinib, overall patient quality of life and symptom burden did not differ between RAM + ERL and PBO + ERL [25]. The majority of AEs associated with RAM + ERL were predictable, and prevention and management measures can be put in place to effectively manage these AEs and reduce the impact of treatment on quality of life. Guidelines for managing the most common AEs associated with EGFR-TKIs have been developed to support healthcare professionals in clinical practice [26]. Treatments are intended as palliative treatments, aimed at symptom relief and improving quality of life. Therefore, in this setting, a predictable, easily detectable, and manageable safety profile could be considered of importance.
Potential limitations were that safety analyses were presented descriptively, with no formal statistical comparisons. In addition, patients with central nervous system metastasis were not eligible, not for safety reasons but in line with contemporary clinical trials in this patient population at the time of study development. This may have resulted in a study population enriched with patients with a better prognosis, producing a more favorable safety profile than might occur in patients with EGFR exon 19 deletion or exon 21 (L858R) mutation-positive metastatic NSCLC in clinical practice.

\section{Conclusions}

This in-depth safety analysis from the RELAY trial supports that RAM + ERL, irrespective of an increased incidence of AEs, did not affect the possibility of patients benefiting from treatment, as reflected by the 7-month increase in median PFS for patients in the RAM + ERL arm compared with those in the PBO + ERL arm. The overall incidence of grade $\geq 3$ AEs was greater with RAM + ERL than with PBO + ERL, with hypertension, dermatitis, and diarrhea reported more frequently in the RAM + ERL arm than in the PBO + ERL arm. The safety profile by race (Asian and non-Asian) was similar to that of the overall population, whereas the incidence of grade $\geq 3$ AEs was greater among patients aged $\geq 70$ years in the RAM +ERL arm. Therefore, the balance of benefits and potential risks for an individual patient should be considered, particularly for elderly patients, when discussing treatment with antiangiogenic agents. The increased rate of AEs can be detected with routine monitoring and managed through dose adjustments and appropriate supportive care. Overall, RAM + ERL offers a tolerable and effective option for the first-line treatment of EGFR exon 19 deletion or exon 21 (L858R) mutation-positive metastatic NSCLC.

Supplementary Information The online version contains supplementary material available at https://doi.org/10.1007/s40264-021-01127-2.

Acknowledgements The authors thank the investigators, the patients, and their families for their contribution to this clinical study. The authors acknowledge John Hurley, Eli Lilly and Company, for medical writing assistance with the preparation of this manuscript, funded by Eli Lilly and Company.

\section{Declarations}

Funding This study was funded by Eli Lilly and Company.

Conflicts of Interest EN has received research grants from Bristol Myers Squibb, Merck Serono, Roche, and Pfizer; advisory board fees from Bristol Myers Squibb, Merck Sharp \& Dohme, Roche, Amgen, Pfizer, Eli Lilly and Company, Takeda, Sanofi, Bayer, AstraZeneca, and Merck Serono; and lecturing/presentation/writing payments from 
Bristol Myers Squibb, Merck Sharp \& Dohme, Roche, Amgen, Pfizer, Eli Lilly and Company, Takeda, Bayer, AstraZeneca, and Boehringer Ingelheim. $\mathrm{HH}$ has received lecture fees, honoraria, or other fees from Eli Lilly and Company, AstraZeneca, Merck Sharp \& Dohme, Ono, and Bristol Myers Squibb and research grants from Merck Sharp \& Dohme, Chugai, Ono, Bristol Myers Squibb, AstraZeneca, Daiichi Sankyo, Novartis, and Genomic Health. JYS has served as an advisory board member for AstraZeneca, Roche, Boehringer Ingelheim, Eli Lilly, Pfizer, Novartis, Merck Sharp \& Dohme, Chugai Pharma, Ono Pharmaceutical, Takeda, CStone Pharmaceuticals, Janssen, and Bristol Myers Squibb; has received speaking honoraria from AstraZeneca, Roche, Boehringer Ingelheim, Eli Lilly, Pfizer, Novartis, Merck Sharp \& Dohme, Chugai Pharma, Ono Pharmaceutical, and Bristol Myers Squibb; and has received a research grant from Roche. $\mathrm{KN}$ has received grants and personal fees from AstraZeneca K.K., Astellas Pharma, Merck Sharp \& Dohme K.K., Ono Pharmaceutical, Nippon Boehringer Ingelheim, Novartis Pharma K.K., Pfizer Japan, Bristol Myers Squibb, Eli Lilly Japan K.K., Chugai Pharmaceutical, Daiichi Sankyo, and Merck Serono; personal fees from Medicus Shuppan, Publishers Co., Ltd, Care Net, Reno, Kyorin, Roche Diagnostics K.K., Bayer Yakuhin, Medical Mobile Communications Co., 3H Clinical Trial, Nanzando, Yodosha, Nikkei Business Publications, Thermo Fisher Scientific K.K., Yomiuri Telecasting Corporation, Nippon Kayaku, and Nichi-Iko Pharmaceutical; grants and personal fees from Takeda Pharmaceutical, Taiho Pharmaceutical, SymBio Pharmaceuticals, and AbbVie; and grants from inVentiv Health Japan, Icon Japan K.K., Gritstone Oncology, Parexel International, Kissei Pharmaceutical, EPS Corporation, Syneos Health, Pfizer R\&D Japan G.K., A2 Healthcare, Quintiles Inc/IQVIA Services Japan K.K., EP-CRSU, Linical, Eisai, CMIC Shift Zero K.K., Kyowa Hakko Kirin, Bayer Yakuhin, EPS International, and Otsuka Pharmaceutical. MR has received personal fees from Amgen, AstraZeneca, Bristol Myers Squibb, Boehringer Ingelheim, Eli Lilly and Company, Merck, Merck Sharp \& Dohme, Novartis, Pfizer, Roche, and Samsung. EBG has received grants from AstraZeneca, Dynavax, Eli Lilly and Company, Genentech, Iovance, Mirati and Neon; grants and personal fees from Bristol Myers Squibb, EMD Serono, Merck, and Novartis; and personal fees from ABL, Boehringer Ingelheim, Dracen, Eisai, GSK, Sanofi, Shionogi, and Xilio. Y-FW has no conflicts of interest that are directly relevant to the content of this article. JK has served as an advisory board member for, without receiving any personal fees from, Roche Pharma, Boehringer Ingelheim, Bristol Myers Squibb, Merck Sharp \& Dohme, Takeda, Astra Zeneca, Amgen, and Eli Lilly and Company. BFM, EB, OL, and CVG are employees of and own stock in Eli Lilly and Company. SN has received speaker bureau/advisor personal fees from Amgen, AstraZeneca, Boehringer, Beigene, Merck Sharp \& Dohme, Roche, Sanofi, Novartis, Takeda, and Pfizer.

Availability of data and material These clinical trial data can be requested by qualified researchers and will be provided following review and approval of a research proposal and execution of a data sharing agreement. For more information on the data request process or to submit a request, visit the following link: https://www.abbvie.com/ our-science/clinical-trials/clinical-trials-data-and-information-sharing/ data-and-information-sharing-with-qualified-researchers.html.

\section{Code availability Not applicable.}

Ethics approval The study was conducted in accordance with the 1964 Declaration of Helsinki and its later amendments, the International Conference on Harmonisation Guidelines for Good Clinical Practice, and applicable local regulations. It was approved by the ethics committees of participating centers.

Consent to participate All patients provided written informed consent prior to participation in the study.
Consent for publication All authors approved this manuscript for publication.

Author contributions All authors contributed to the intellectual content of the work through conception; design; data acquisition, analysis, and interpretation; and the drafting and critical review of the manuscript. All authors provided their final approval of the manuscript.

Open Access This article is licensed under a Creative Commons Attribution-NonCommercial 4.0 International License, which permits any non-commercial use, sharing, adaptation, distribution and reproduction in any medium or format, as long as you give appropriate credit to the original author(s) and the source, provide a link to the Creative Commons licence, and indicate if changes were made. The images or other third party material in this article are included in the article's Creative Commons licence, unless indicated otherwise in a credit line to the material. If material is not included in the article's Creative Commons licence and your intended use is not permitted by statutory regulation or exceeds the permitted use, you will need to obtain permission directly from the copyright holder. To view a copy of this licence, visit http://creativecommons.org/licenses/by-nc/4.0/.

\section{References}

1. Roeper J, Kurz S, Grohé C, Griesinger F. Optimizing therapy sequence to prevent patient attrition in EGFR mutationpositive advanced or metastatic NSCLC. Future Oncol. 2021;17(4):471-86.

2. Girard N. Optimizing outcomes and treatment sequences in EGFR mutation-positive non-small-cell lung cancer: recent updates. Future Oncol. 2019;15(25):2983-97.

3. Wu YL, Planchard D, Lu S, Sun H, Yamamoto N, Kim DW, et al. Pan-Asian adapted clinical practice guidelines for the management of patients with metastatic non-small-cell lung cancer: a CSCO-ESMO initiative endorsed by JSMO, KSMO, MOS, SSO and TOS. Ann Oncol. 2019;30(2):171-210.

4. Saito H, Fukuhara T, Furuya N, Watanabe K, Sugawara S, Iwasawa $S$, et al. Erlotinib plus bevacizumab versus erlotinib alone in patients with EGFR-positive advanced non-squamous nonsmall-cell lung cancer (NEJ026): interim analysis of an openlabel, randomised, multicentre, Phase 3 trial. Lancet Oncol. 2019;20(5):625-35.

5. Seto T, Kato T, Nishio M, Goto K, Atagi S, Hosomi Y, et al. Erlotinib alone or with bevacizumab as first-line therapy in patients with advanced non-squamous non-small-cell lung cancer harbouring EGFR mutations (JO25567): an open-label, randomised, multicentre, Phase 2 study. Lancet Oncol. 2014;15(11):1236-44.

6. Zhou Q, Cheng Y, Liu YP, Chen GY, Cui JW, Yang N, et al. Bevacizumab plus erlotinib in chinese patients with untreated, EGFR-mutated, advanced NSCLC (ARTEMIS-CTONG1509): a multicenter phase 3 study. Cancer Cell. 2021;39(9):1279-91.

7. Apte RS, Chen DS, Ferrara N. VEGF in signaling and disease: beyond discovery and development. Cell. 2019;176(6):1248-64.

8. Nakagawa K, Garon EB, Seto T, Nishio M, Ponce Aix S, Paz-Ares $\mathrm{L}$, et al. Ramucirumab plus erlotinib in patients with untreated, $E G F R$-mutated, advanced non-small-cell lung cancer (RELAY): a randomised, double-blind, placebo-controlled, Phase 3 trial. Lancet Oncol. 2019;20(12):1655-69.

9. Thomas DG, Algorithm AS. 36: Exact confidence limits for the odds ratio in a $2 \times 2$ table. J R Stat Soc Ser C (Appl Stat). 1971;20(1):105-10. https://doi.org/10.2307/2346643.

10. Fuchs CS, Tomasek J, Yong CJ, Dumitru F, Passalacqua R, Goswami $\mathrm{C}$, et al. Ramucirumab monotherapy for previously treated 
advanced gastric or gastro-oesophageal junction adenocarcinoma (REGARD): an international, randomised, multicentre, placebocontrolled, phase 3 trial. Lancet. 2014;383(9911):31-9.

11. Garon EB, Ciuleanu TE, Arrieta O, Prabhash K, Syrigos KN, Goksel T, et al. Ramucirumab plus docetaxel versus placebo plus docetaxel for second-line treatment of stage IV non-small-cell lung cancer after disease progression on platinum-based therapy (REVEL): a multicentre, double-blind, randomised phase 3 trial. Lancet. 2014;384(9944):665-73.

12. Petrylak DP, de Wit R, Chi KN, Drakaki A, Sternberg CN, Nishiyama $\mathrm{H}$, et al. Ramucirumab plus docetaxel versus placebo plus docetaxel in patients with locally advanced or metastatic urothelial carcinoma after platinum-based therapy (RANGE): a randomised, double-blind, phase 3 trial. Lancet. 2017;390(10109):2266-77.

13. Tabernero J, Yoshino T, Cohn AL, Obermannova R, Bodoky G, Garcia-Carbonero R, et al. Ramucirumab versus placebo in combination with second-line FOLFIRI in patients with metastatic colorectal carcinoma that progressed during or after first-line therapy with bevacizumab, oxaliplatin, and a fluoropyrimidine (RAISE): a randomised, double-blind, multicentre, phase 3 study. Lancet Oncol. 2015;16(5):499-508.

14. Wilke H, Muro K, Van Cutsem E, Oh SC, Bodoky G, Shimada $\mathrm{Y}$, et al. Ramucirumab plus paclitaxel versus placebo plus paclitaxel in patients with previously treated advanced gastric or gastro-oesophageal junction adenocarcinoma (RAINBOW): a double-blind, randomised phase 3 trial. Lancet Oncol. 2014;15(11):1224-35.

15. Zhu AX, Park JO, Ryoo BY, Yen CJ, Poon R, Pastorelli D, et al. Ramucirumab versus placebo as second-line treatment in patients with advanced hepatocellular carcinoma following first-line therapy with sorafenib (REACH): a randomised, double-blind, multicentre, phase 3 trial. Lancet Oncol. 2015;16(7):859-70.

16. Nakagawa K, Nadal E, Garon EB, Nishio M, Seto T, Yamamoto N, et al. RELAY, erlotinib plus ramucirumab or placebo in untreated EGFR-mutated metastatic NSCLC: outcomes by EGFR mutation type (Abstract 1294P). Ann Oncol. 2020;31(Suppl 4):S838.

17. Stinchcombe TE, Jänne PA, Wang X, Bertino EM, Weiss J, Bazhenova L, et al. Effect of erlotinib plus bevacizumab vs erlotinib alone on progression-free survival in patients with advanced EGFR-mutant non-small cell lung cancer: a Phase 2 randomized clinical trial. JAMA Oncol. 2019;5(10):1448-55.
18. Elice F, Rodeghiero F. Side effects of anti-angiogenic drugs. Thromb Res. 2012;129(Suppl 1):S50-3.

19. Hayman SR, Leung N, Grande JP, Garovic VD. VEGF inhibition, hypertension, and renal toxicity. Curr Oncol Rep. 2012;14(4):285-94.

20. Estrada CC, Maldonado A, Mallipattu SK. Therapeutic inhibition of VEGF signaling and associated nephrotoxicities. J Am Soc Nephrol. 2019;30(2):187-200.

21. Nishio M, Seto T, Reck M, Garon EB, Chiu CH, Yoh K, et al. Ramucirumab or placebo plus erlotinib in EGFR-mutated, metastatic non-small-cell lung cancer: East Asian subset of RELAY. Cancer Sci. 2020;111(12):4510-25.

22. Aix SP, Novello S, Garon EB, Nakagawa K, Nadal E, Moro-Sibilot $\mathrm{D}$, et al. RELAY, ramucirumab plus erlotinib versus placebo plus erlotinib in patients with untreated, EGFR-mutated, metastatic non-small cell lung cancer: Europe/United States subset analysis. Cancer Treat Res Commun. 2021;27: 100378.

23. Langer CJ, Socinski MA, Patel JD, Sandler AB, Schiller JH, Leon $\mathrm{L}$, et al. Isolating the role of bevacizumab in elderly patients with previously untreated nonsquamous non-small cell lung cancer: secondary analyses of the ECOG 4599 and pointbreak trials. Am J Clin Oncol. 2016;39(5):441-7.

24. Fukuda M, Kitazaki T, Ogawara D, Ichiki M, Mukae H, Maruyama R, et al. Randomized phase II study of pemetrexed or pemetrexed plus bevacizumab for elderly patients with previously untreated non-squamous non-small cell lung cancer: results of the Lung Oncology Group in Kyushu (LOGIK1201). Lung Cancer. 2019;132:1-8.

25. Yoh K, Atagi S, Reck M, Garon EB, Ponce Aix S, Moro-Sibilot $\mathrm{D}$, et al. Patient-reported outcomes in RELAY, a phase 3 trial of ramucirumab plus erlotinib versus placebo plus erlotinib in untreated EGFR-mutated metastatic non-small-cell lung cancer. Curr Med Res Opin. 2020;36(10):1667-75.

26. Califano R, Tariq N, Compton S, Fitzgerald DA, Harwood CA, $\mathrm{Lal} \mathrm{R}$, et al. Expert consensus on the management of adverse events from EGFR tyrosine kinase inhibitors in the UK. Drugs. 2015;75(12):1335-48.

27. Eli Lilly and Company. 2019

\section{Authors and Affiliations}

\section{Ernest Nadal ${ }^{1}\left[\right.$ D Hidehito Horinouchi ${ }^{2} \cdot$ Jin-Yuan Shih $^{3} \cdot$ Kazuhiko Nakagawa $^{4} \cdot$ Martin Reck $^{5} \cdot$ Edward B. Garon $^{6}$. Yu-Feng Wei ${ }^{7}$. Jens Kollmeier ${ }^{8}$. Bente Frimodt-Moller ${ }^{9}$. Emily Barrett ${ }^{10}$. Olga Lipkovich ${ }^{11}$. Carla Visseren-Grul ${ }^{12}$. Silvia Novello ${ }^{13}$}

1 Catalan Institute of Oncology, IDIBELL, L'Hospitalet, Barcelona, Spain

2 National Cancer Center Hospital, Tokyo, Japan

3 National Taiwan University Hospital, Taipei City, Taiwan

4 Faculty of Medicine, Kindai University, Osaka, Japan

5 LungenClinic, Airway Research Center North, German Center for Lung Research, Grosshansdorf, Germany

6 David Geffen School of Medicine at UCLA/Translational Research in Oncology-US Network, Santa Monica, CA, USA
7 E-Da Cancer Hospital, I-Shou University, Kaohsiung City, Taiwan

8 Helios Klinikum Emil von Behring, Berlin, Germany

9 Eli Lilly and Company, Copenhagen, Denmark

10 Eli Lilly and Company, Bracknell, UK

11 Eli Lilly and Company, Indianapolis, IN, USA

12 Lilly Oncology, Utrecht, Netherlands

13 Department of Oncology, University of Turin, A.O.U. San Luigi Gonzaga, Turin, Italy 